\title{
Assimilation of Remotely Sensed Leaf Area Index into the Noah-MP Land Surface Model: Impacts on Water and Carbon Fluxes and States over the Continental United States
}

\author{
SUJAY V. KUMAR \\ Hydrological Sciences Laboratory, NASA GSFC, Greenbelt, Maryland \\ DAvid M. Mocko AND SHUGONG WANG \\ Science Applications International Corporation, Hydrological Sciences Laboratory, \\ NASA GSFC, Greenbelt, Maryland \\ CHRISTA D. PETERS-LIDARD \\ Hydrosphere, Biosphere, and Geophysics, Earth Sciences Division, NASA GSFC, Greenbelt, Maryland \\ JORDAN BORAK \\ Earth System Science Interdisciplinary Center, Hydrological Sciences Laboratory, \\ NASA GSFC, Greenbelt, Maryland
}

(Manuscript received 16 November 2018, in final form 16 April 2019)

\begin{abstract}
Accurate representation of vegetation states is required for the modeling of terrestrial water-energycarbon exchanges and the characterization of the impacts of natural and anthropogenic vegetation changes on the land surface. This study presents a comprehensive evaluation of the impact of assimilating remote sensing-based leaf area index (LAI) retrievals over the continental United States in the NoahMP land surface model, during a time period of 2000-17. The results demonstrate that the assimilation has a beneficial impact on the simulation of key water budget terms, such as soil moisture, evapotranspiration, snow depth, terrestrial water storage, and streamflow, when compared with a large suite of reference datasets. In addition, the assimilation of LAI is also found to improve the carbon fluxes of gross primary production (GPP) and net ecosystem exchange (NEE). Most prominent improvements in the water and carbon variables are observed over the agricultural areas of the United States, where assimilation improves the representation of vegetation seasonality impacted by cropping schedules. The systematic, added improvements from assimilation in a configuration that employs high-quality boundary conditions highlight the significant utility of LAI data assimilation in capturing the impacts of vegetation changes.
\end{abstract}

\section{Introduction}

In recognition of the intimate linkages between the terrestrial water and carbon cycles, the focus of land surface models (LSMs) in recent years has extended to include more detailed representations of the carbon cycle processes (Niyogi et al. 2009; Sato et al. 2015). Characterization of biogeochemical processes such as photosynthesis, respiration and leaf phenology is

Corresponding author: Sujay V. Kumar, sujay.v.kumar@nasa.gov important for the accurate representation of stomatal response, which is the key factor in the determination of transpiration and evapotranspiration (Jasechko et al. 2013; Schlesinger and Jasechko 2014). The increased transpiration due to vegetation presence, particularly over mid- and low latitudes, leads to the cooling of the land surface. Vegetation also reduces the surface albedo, which increases the amount of absorbed radiation, impacting snow evolution and melt (Essery et al. 2003; Niu and Yang 2004). The simultaneous representation of water, energy, and biogeochemical cycle processes in 
LSMs is necessary for representing the water-energycarbon exchanges and feedbacks that are relevant at various spatial and temporal scales. Further, detailed characterization of vegetation and canopy physical states is also needed for the modeling of agricultural and crop management practices (McDermid et al. 2017) and the impact of vegetation disturbances on the land surface (Liu et al. 2005; Garcia et al. 2014).

Leaf area index (LAI), defined as the total leaf area over a unit of ground area, essentially represents the potential surface area available for photosynthesis. As a variable that controls the carbon, energy, and water balance in plants (Cowling and Field 2003), LAI is a key parameter in models of land surface and phenology. Most modern (third generation) LSMs include formulations of LAI, either as a parameterization based on vegetation type or prescribed from climatological values (Sellers et al. 1997; Pitman 2003). The further development of submodels of vegetation dynamics in LSMs (Dickinson et al. 1998; Niu et al. 2011) has enabled the prognostic representation of LAI and other vegetation states, allowing the inclusion of observational constraints in modeling.

Remote sensing measurements, particularly from optical sensors, have provided high-resolution measurements of canopy states such as LAI, normalized difference vegetation index (NDVI), fraction of photosynthetically active radiation (fPAR), and biomass, among others (Myneni et al. 2002; Tucker et al. 2005; Zheng and Moskal 2009; Myneni et al. 2011; Kumar and Mutanga 2017), in the past 10-15 years. As these measurements have gaps in their spatial and temporal coverage, methods such as data assimilation (DA) are often used to incorporate the information content of observations in models for developing spatially and temporally continuous estimates. As demonstrated in DA studies of water cycle measurements (Reichle et al. 2007; Liu et al. 2011; Kumar et al. 2014; De Lannoy et al. 2012; Dziubanski and Franz 2016; Zaitchik and Rodell 2009; Peters-Lidard et al. 2011; Zhang et al. 2014), DA methods also allow the extension of remote sensing observations (which are often limited to the surface states only) to other important processes such as root zone soil moisture, evapotranspiration and streamflow. Similarly, there have been numerous studies of assimilating remotely sensed vegetation variables into crop and land surface models. The assimilation of LAI observations was shown to improve the estimation of yields for crops such as wheat (Dente et al. 2008; Xie et al. 2017) and maize (Ines et al. 2013; Wang et al. 2014). A review of such DA efforts is summarized in Jin et al. (2018). Studies of assimilating LAI estimates (e.g., Sabater et al. 2008; Barbu et al. 2011, 2014; Albergel et al. 2017, 2018) have also been used to improve the estimation of vegetation biomass, evapotranspiration, root zone soil moisture, and $\mathrm{CO}_{2}$ fluxes within land surface models.

In this study, we demonstrate the assimilation of remotely sensed LAI estimates in the Noah multiparameterization (Noah-MP) LSM over the continental United States (CONUS) in the North American Land Data Assimilation System phase 2 (NLDAS-2) configuration. NLDAS (Mitchell et al. 2004; Xia et al. 2012b) is an operational system at NOAA/NCEP that runs multiple land surface models in an uncoupled manner forced with high-quality forcing inputs including gauge-based precipitation and bias-corrected shortwave radiation and surface meteorology reanalysis. The model outputs from NLDAS-2 are used to support a wide variety of land modeling research and water resources management applications, including operational drought monitoring and prediction. The planned enhancements to the NLDAS system include the upgrade of the LSMs to newer versions and models such as Noah-MP. In addition, the incorporation of data assimilation instances, currently lacking in the operational NLDAS, is another key emphasis of the next phase of NLDAS-2 development (Ek et al. 2017). Recent efforts, focused primarily on the assimilation of water cycle observations, have quantified the positive impacts of assimilating remotely sensed soil moisture, snow depth, snow cover and terrestrial water storage measurements, individually and concurrently, in the NLDAS-2 environment (Kumar et al. 2014, 2015, 2016, 2019). This article presents a continuation of these efforts, by describing the assimilation of remotely sensed vegetation data into the NLDAS-2 configuration. The impact of LAI assimilation on energy, water, and carbon cycle states is examined through a comprehensive evaluation using independent measurements and reference data products.

LAI estimates from the University of Maryland Global Land Cover Facility (GLCF) Global Land Surface Satellites (GLASS; Xiao et al. 2016) are employed for data assimilation within Noah-MP. The GLASS LAI product represents a long-term (from 1981 to present), global LAI product generated from the Advanced Very High Resolution Radiometer (AVHRR) and Moderate Resolution Imaging Spectroradiometer (MODIS) reflectance datasets. The availability of the long time series of the LAI record has facilitated studies of land use change impacts and agricultural sustainability (Zhu et al. 2016; Huang et al. 2016; Zhu et al. 2017). MODISbased GLASS LAI V4 product, available from 2000 to present, is employed in this study.

The article is organized as follows: section 2 contains descriptions of the model and data assimilation 

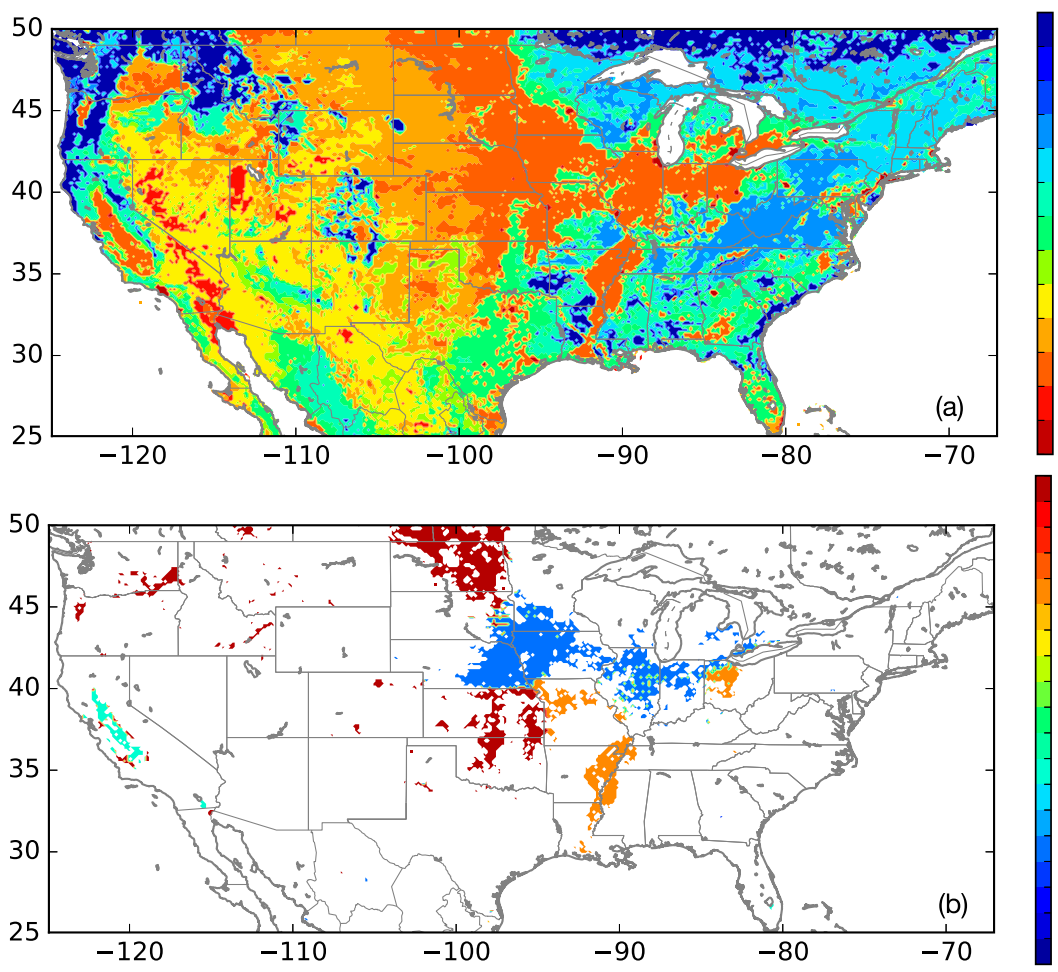

FIG. 1. Maps of (top) dominant land cover using UMD classification and (bottom) the detailed crop classification for the cropland vegetation type. Note that the detailed crop map is not used in the model simulations.
Evergreen Needleleaf Forest Broadleaf Needleleaf Forest Deciduous Needleleaf Forest Deciduous Broadleaf Forest Mixed Forests Woodlands Wooded Grasslands Closed Shrublands Open Shrublands Grasslands Croplands Bare Soil Urban

Wheat Sunflower

Sugar cane

Sugar beets Soy

Sorghum

Rye

Rice

Rape

Potatoes

Others

Oil palm

Millet

Maize

Ground nut

Cotton

Cassava

Barley configurations. The description and analysis of the results are presented in section 3. A summary and major conclusions are described in 4 .

\section{Study settings}

\section{a. Model configuration}

All model simulations are conducted using a configuration similar to that used in NLDAS-2. The model grid spans the CONUS $\left(25^{\circ}-53^{\circ} \mathrm{N}, 125^{\circ}-67^{\circ} \mathrm{W}\right)$ at $1 / 8^{\circ}$ spatial resolution. The static vegetation map using the University of Maryland (UMD) land cover classification (Hansen et al. 2000) shown in Fig. 1a is used in the model runs. Figure $1 \mathrm{~b}$ shows a more detailed representation of the croplands based on Leff et al. (2004). The major crop types of wheat (over North Dakota, Kansas), maize (over Nebraska, Iowa, Illinois, and Indiana), soybean (over the lower Mississippi basin, Ohio), and others (central California, Florida) are represented in Fig. 1b. Note that only the vegetation map shown in Fig. 1a is used in the model runs, whereas the detailed crop classification in Fig. 1b is shown primarily for the purpose of examining the spatial patterns of the impact of LAI assimilation. The model simulations are forced with the NLDAS-2 meteorology (Xia et al. 2012a), which includes gauge-based daily precipitation temporally disaggregated with radar data, bias corrected shortwave radiation, and surface meteorological analysis. The NASA Land Information System (LIS; Kumar et al. 2006; PetersLidard et al. 2007) framework, a widely used land surface modeling and data assimilation system, is employed for conducting all model integrations.

The Noah-MP model (Niu et al. 2011; Yang et al. 2011) represents the community efforts to extend the capabilities of the Noah LSM through the incorporation of multiple and new physics capabilities. The physics enhancements in Noah-MP include multilayer snowpack, multiple options for surface water infiltration, runoff, and groundwater, including the representation of an unconfined water table depth (Niu et al. 2007), among numerous other options. A key enhancement relevant for this study is the inclusion of a dynamic phenology model allowing for the prognostic representation of vegetation growth and senescence. Noah-MP integrates a Ball-Berry photosynthesis-based stomatal resistance model (Ball et al. 1987) with the dynamic vegetation model of Dickinson et al. (1998). The model explicitly models the carbon storages in the leaf, stem, wood, and root parts of the vegetation. The availability of these prognostic vegetation states allows for the assimilation of observations of vegetation conditions such as LAI. 

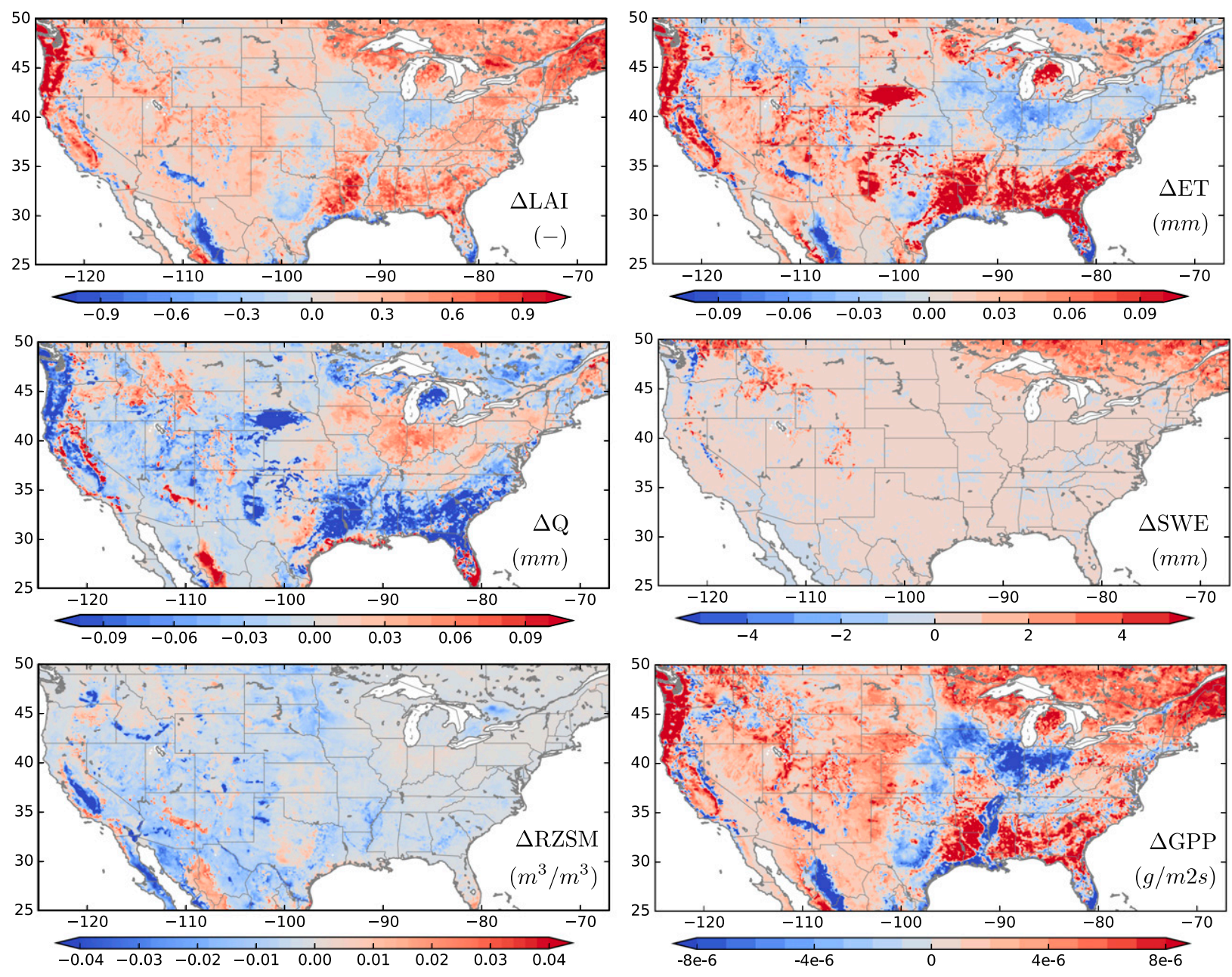

FIG. 2. Changes in the mean LAI, ET, $Q$, SWE, RZSM, and GPP as a result of LAI assimilation.

The initial conditions for the LSM are generated by conducting a model spinup starting with uniform conditions and running the model from 1979 to 2017 twice. The model is then reinitialized in 1979 using climatological average conditions based on the spinup. The gridded surface runoff and baseflow fields from Noah-MP are employed by the Hydrological Modeling and Analysis Platform (HyMAP; Getirana et al. 2012) streamflow routing model to generate estimates of routed streamflow. HyMAP is run over the same model grid as the LSM. Note that the influence of lakes and reservoirs and the management impacts from reservoir operations are not modeled in this study. The feedback from the routing model to the LSM moisture states is also not modeled.

\section{b. Data assimilation configuration}

The data assimilation integrations are conducted using a one-dimensional ensemble Kalman filter (EnKF; Reichle et al. 2002) algorithm implemented in LIS, which has been demonstrated for many sequential data assimilation studies (Reichle et al. 2010; De Lannoy et al. 2012; Kumar et al. 2014; Liu et al. 2015; Kumar et al. 2019). The model ensemble is created by applying small perturbations to the meteorological forcing inputs and the model states, at each grid point. Similar to prior studies (Kumar et al. 2014, 2019), the precipitation $P$ and downward shortwave radiation (SW) fields are perturbed with multiplicative perturbations with a mean of 1 and standard deviations of 0.3 and 0.5 , respectively. Additive perturbations with a standard deviation of $50 \mathrm{~W} \mathrm{~m}^{-2}$ are applied to the downward longwave radiation (LW) fields. The forcing perturbations are applied hourly and include cross correlations $\rho$ to perturbations between forcing fields $[\rho(\mathrm{SW}, P)=-0.8, \rho(\mathrm{SW}, \mathrm{LW})=$ $-0.5, \rho(\mathrm{LW}, P)=0.5]$, based on Kumar et al. (2014). The state vector used in the DA configuration consists of only one variable, the prognostic LAI. Though related, including other variables such as soil moisture in the state vector requires the consideration of temporal lags in the relationship between soil moisture and LAI 

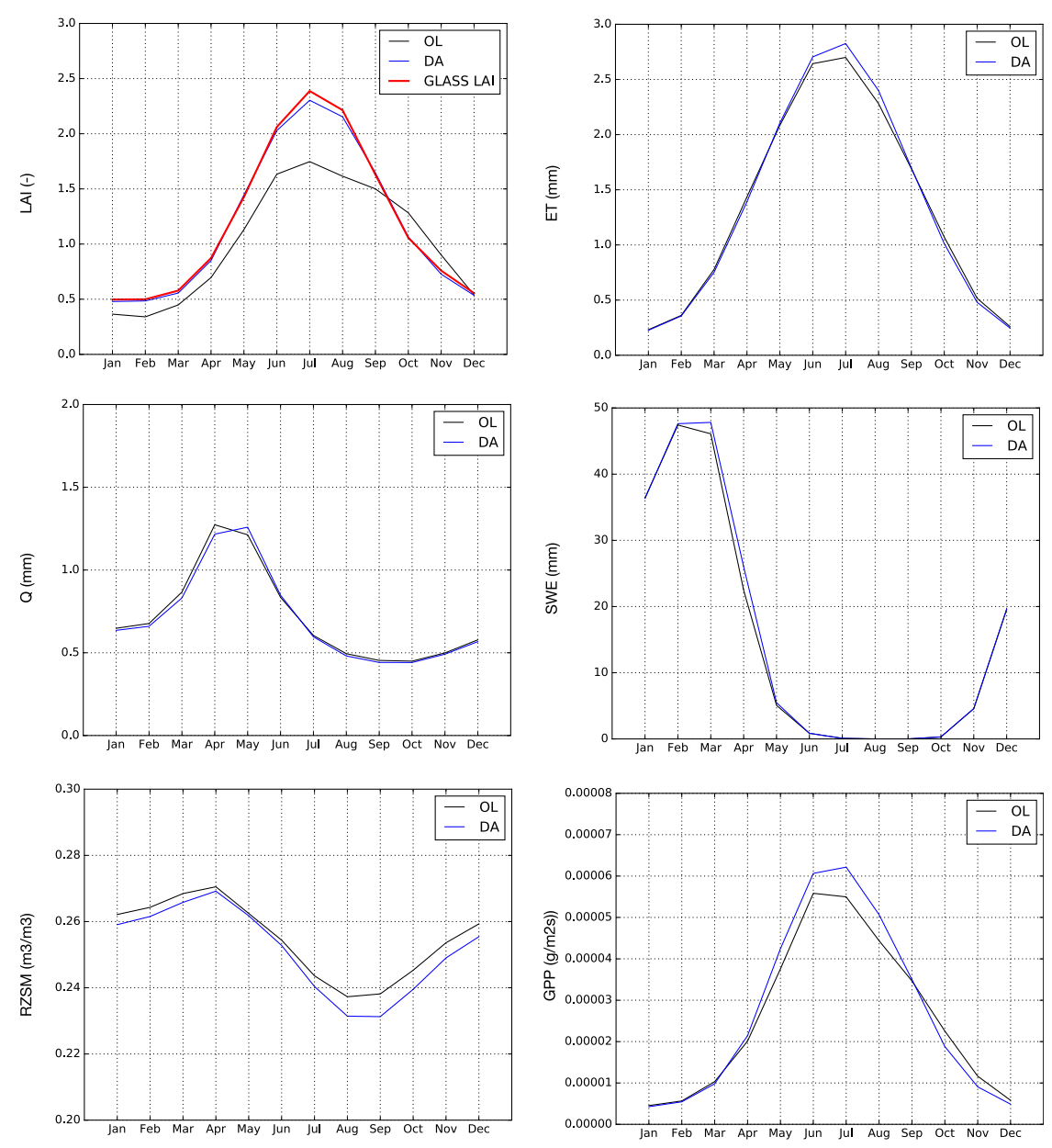

FIG. 3. Domain averaged mean seasonal cycle of LAI, ET, $Q$, SWE, RZSM, and GPP from the OL and DA integrations. The seasonal cycle of LAI from the GLASS dataset is also shown.

(Crow et al. 2012) and the influence of soil and vegetation characteristics. As a result, a simple state vector formulation using only LAI, which is the variable most directly connected to the observations, is used. Additive perturbations with a standard deviation of 0.01 are applied to the modeled LAI fields. This error standard deviation level is comparable to the values used in prior LAI assimilation studies (Rudiger et al. 2010; Albergel et al. 2017), albeit with a linearized extended Kalman filter algorithm. The updated LAI from assimilation is also used to update the leaf biomass by dividing the LAI value with the specific leaf area, which varies with vegetation type, consistent with the Noah-MP physics formulations (Liu et al. 2016). Other vegetation mass prognostic variables in Noah-MP related to the stem, wood, and root mass are not updated as part of assimilation. If perturbations or analysis updates lead to unphysical values, those ensemble members are rescaled to valid values using the majority of the valid ensemble members.
The remote sensing-based observations of LAI, obtained from the GLASS LAI product, are generated using a general regression neural network approach (Xiao et al. 2014), allowing a spatially and temporally consistent long-term record of vegetation conditions. The improved spatiotemporal coverage of the GLASS product has been shown to have greater utility over that of the standard MODIS LAI product, which is affected by cloud obscuration gaps (Liang et al. 2013). The validation of the GLASS data and comparison against other LAI products have also demonstrated the high quality of the product (Liao et al. 2012; Fang et al. 2013; Xiao et al. 2016). The GLASS LAI observations are available at 8-day intervals, on a $0.05^{\circ}$ regular latitude-longitude global grid. Daily observations generated through a linear temporal interpolation between the 8-day observations are used in the model simulations. A uniform observation error standard deviation of 0.05 is used in the DA configuration, which is an optimistic estimate of the expected error levels (Xie et al. 2017). Though the 
results in the following section indicate that these settings are reasonable, spatially distributed observation error specifications that better account for the strengths and limitations of the retrievals may be helpful in further improving the utilization of LAI data within data assimilation. Finally, the analysis update does not account for the effects of subgrid vegetation heterogeneity, as the model configuration only uses the dominant vegetation type within each grid cell. As suggested by Munier et al. (2018), differing tendencies from different vegetation types could be an important factor in the upscaled LAI estimates, particularly when the model and observation resolutions differ significantly.

\section{Results}

This section presents a detailed examination of the impact of LAI assimilation on key terrestrial water and carbon states and fluxes. The evaluation includes an assessment of the impact of the changes in these variables as well as comparisons against a number of reference data products. Specifically, modeled estimates of soil moisture, evapotranspiration, streamflow, snow depth, terrestrial water storage (TWS), gross primary productivity (GPP), and net ecosystem exchange (NEE) are compared against a large suite of reference data products. The impact of DA is evaluated by quantifying the performance improvement or degradation relative to the model open-loop (OL) simulation that does not employ any data assimilation. All evaluations are conducted using the NASA Land Surface Verification Toolkit (LVT; Kumar et al. 2012).

Changes in LAI have direct impacts on terrestrial water and carbon fluxes. A decrease in LAI leads to reduced canopy shading, increased net radiation at the surface, and increased soil evaporation. Similarly, an increase in LAI leads to increased transpiration, increased root water update, and reduced soil moisture in the root zone. The increase in LAI also implies increased canopy shading, reduced available net radiation, and reduced snowmelt. GPP, the amount of carbon fixed by photosynthesis, is closely related to transpiration. The increased transpiration from increased LAI also leads to increased carbon fixation and GPP, particularly under water-limited conditions. These first-order impacts on the water and carbon states are seen in Fig. 2, which shows the changes in the mean LAI, evapotranspiration (ET), runoff $Q$, SWE, root zone soil moisture (RZSM), and GPP fields during the 2000-17 period. Relative to the OL simulation, the LAI assimilation leads to increased LAI in most parts of the domain, except over areas near the upper Mississippi basin, parts of the Southern Great Plains (SGP), southwestern Mexico, and southern Florida.
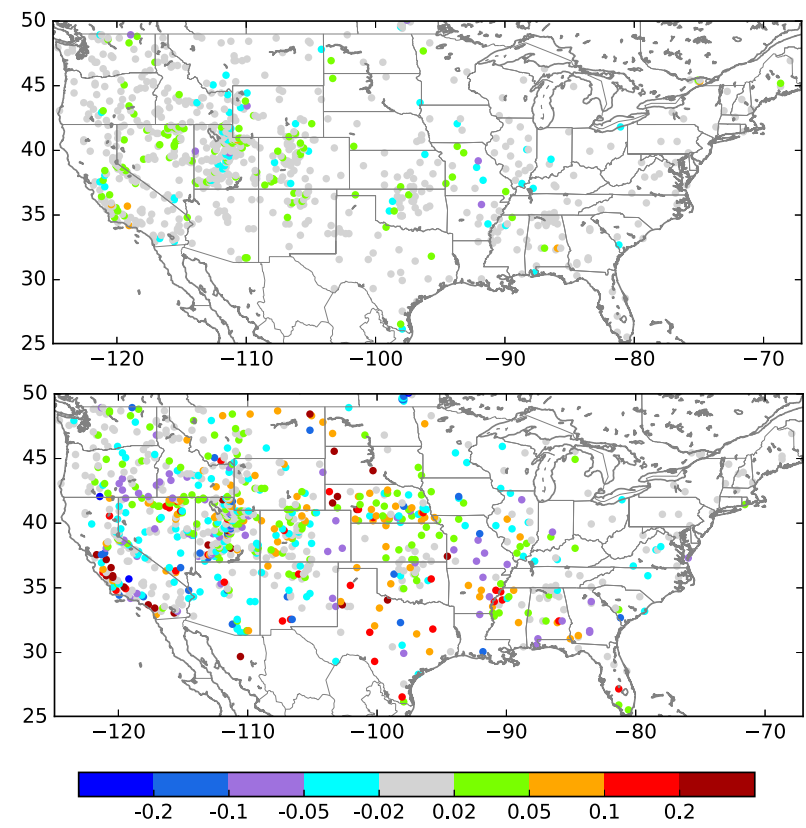

FIG. 4. Differences in anomaly $R$ values (during 2000-17) for (top) surface soil moisture and (bottom) root zone soil moisture from LAI assimilation relative to the OL integration. The warm colors indicate improvements and cool colors represent degradations from DA. The gray shading indicates locations where the differences are not statistically significant.

The increased LAI generally leads to increased evapotranspiration, reduced runoff, increased SWE, drier soil moisture and increased GPP. Conversely, over areas where LAI is reduced, evapotranspiration and GPP reduce and runoff and root zone soil moisture increase.

To examine the influence of LAI assimilation temporally, the domain-averaged mean seasonal cycles of LAI, ET, runoff, SWE, root zone soil moisture, and GPP from OL and DA integrations are shown in Fig. 3. Similar to the trends in Fig. 2, assimilation leads to increased LAI during most months except during October and November. The largest increase in LAI is seen during the summer months of June-August. Correspondingly, the most prominent changes in ET and GPP are also seen during these time periods where DA leads to increased magnitudes of these variables. The seasonal cycle of runoff indicates that DA leads to drier runoff values except during May. Most significant impacts on SWE are seen during the melt periods (March and April), where DA leads to larger snowpacks. Finally, LAI DA leads to drier root zone soil moisture estimates, more prominently during the late summer and fall time periods. In the following sections, the quantitative evaluation of the LAI assimilation impact is presented through comparisons against reference datasets. 


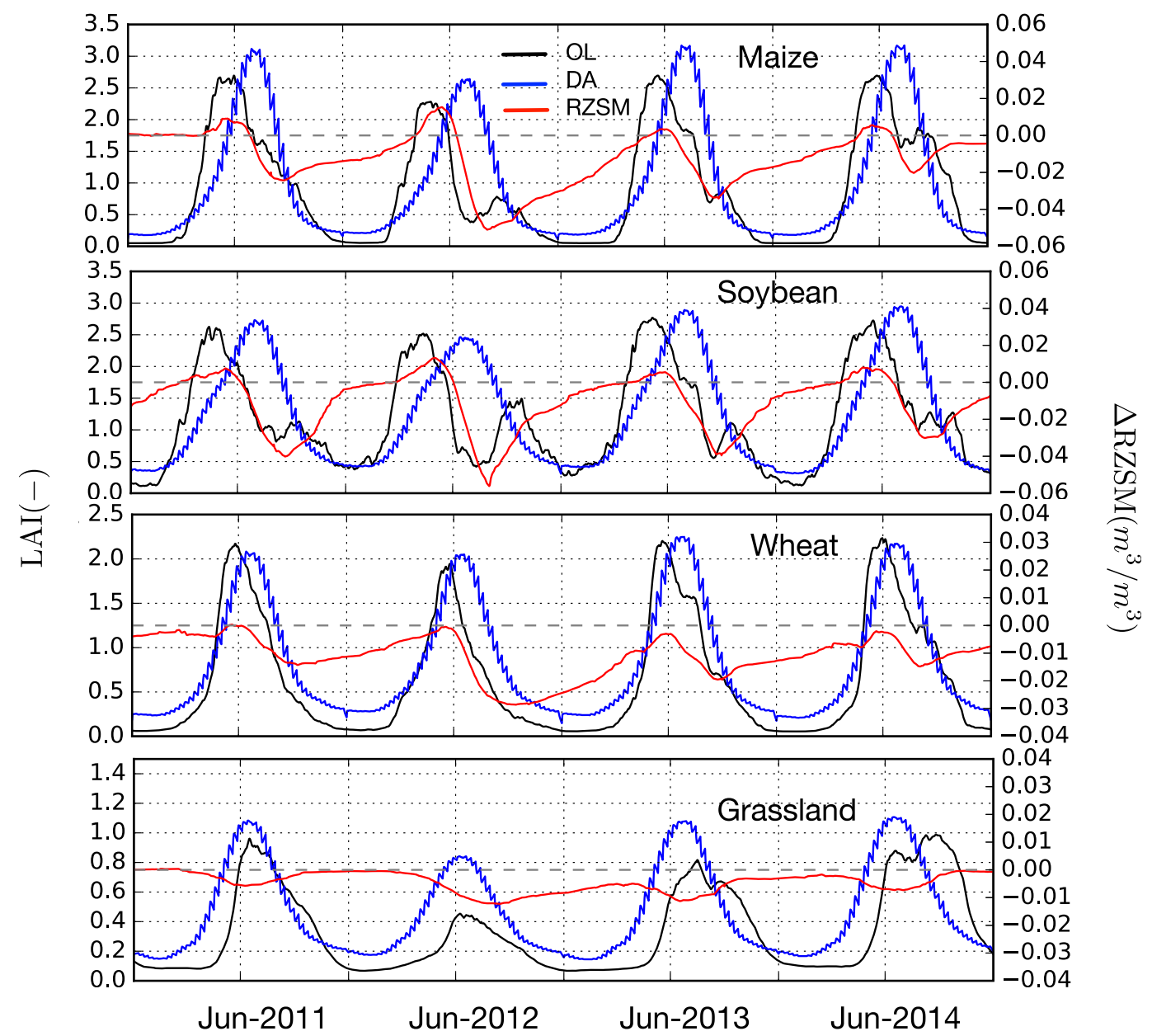

FIG. 5. Time series of area-averaged LAI over maize, soybean, wheat, and grassland areas from OL and DA integrations during 2011-15. The right vertical axis shows time series of differences in the area averaged root zone soil moisture between the DA and OL integrations.

\section{a. Soil moisture}

The modeled surface and root zone soil moisture estimates are compared against in situ measurements from the International Soil Moisture Network (ISMN; Dorigo et al. 2011). ISMN is an integrated, quality controlled database of in situ soil profile measurements from several networks. Datasets from different networks are provided in a consistent format and convention and archived at the highest available temporal resolution up to hourly from each instrument. Hourly data from over 934 stations from nine different networks at depths up to $100 \mathrm{~cm}$ (whenever available) are used in the evaluations in this study. Both modeled and observed root zone soil moisture is computed through weighted (by soil layer thickness) vertical average over individual observation layers within the top $1 \mathrm{~m}$. The data are considered missing if not all profile measurements within the top $1 \mathrm{~m}$ is available. As the modeled and in situ soil moisture measurements have significant biases relative to each other, the skill of the modeled estimates is evaluated using the anomaly correlation (anomaly $R$ ) metric. At each location, the monthly mean soil moisture values are computed first, for both model and observations. The anomaly $R$ values are computed as the correlation of anomalies, which are the differences between the daily soil moisture values and the monthly mean estimates.

Figure 4 shows the change in anomaly correlation $R$ values for surface and root zone soil moisture compared to the OL integration, during 2000-17. The warm colors indicate locations where the assimilation of LAI provides a statistically significant improvement in soil moisture, whereas the cool colors indicate locations where LAI DA leads to degradations. Overall, there is a small, but positive impact in surface soil moisture estimates from LAI assimilation. The improvements are mostly observed in the Central Plains and locations in 

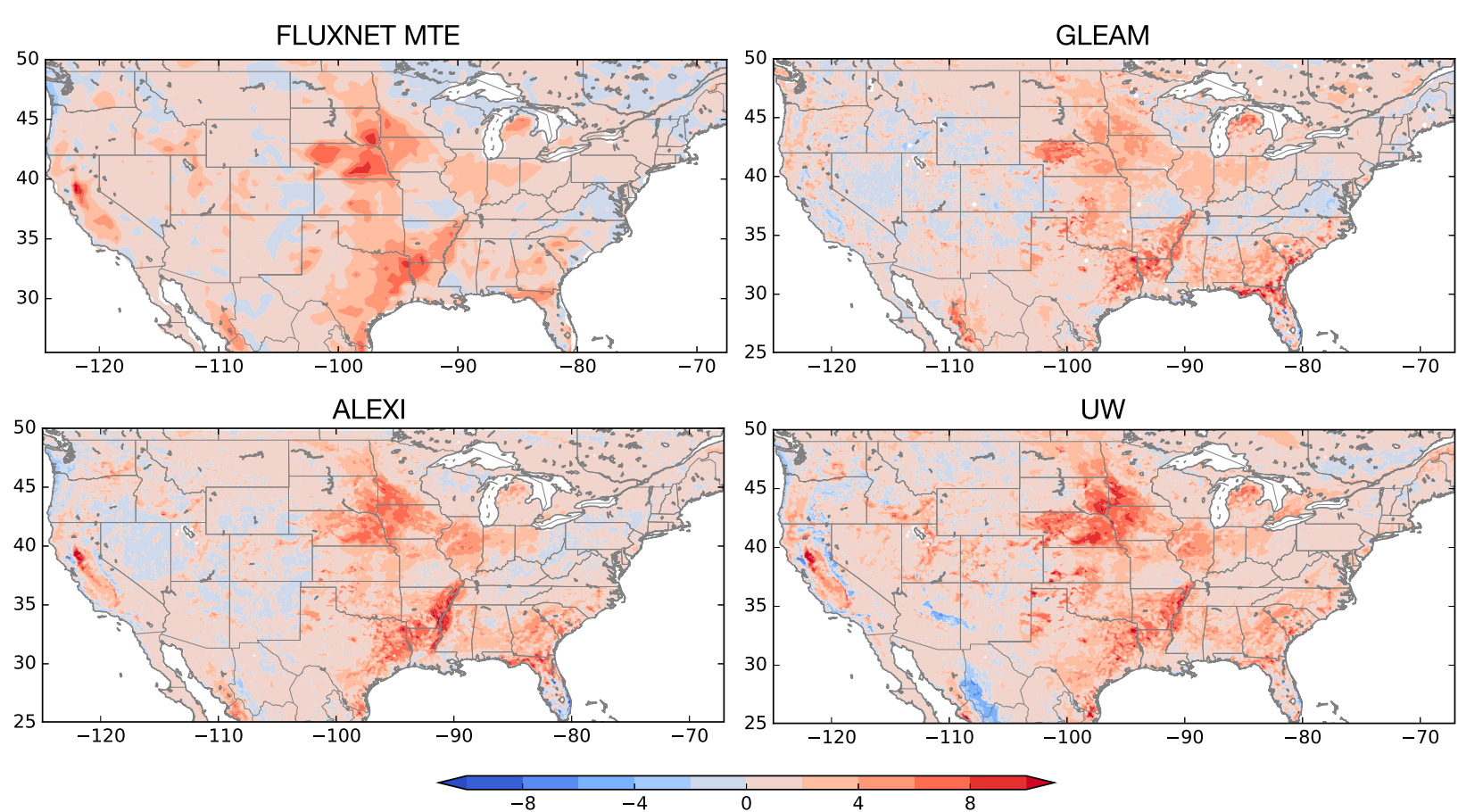

FIG. 6. RMSE differences $\left(\mathrm{W} \mathrm{m}^{-2}\right.$ ) of evapotranspiration from LAI assimilation relative to the OL integration, using four reference datasets. The time periods in the RMSE comparisons are 2000-08, 2000-14, 2000-14, and 2000-08 for FLUXNET MTE, GLEAM, ALEXI, and UW, respectively. The warm colors represent decreases in RMSE, and the cool colors represent increases in RMSE due to LAI DA.

the intermountain West. Comparatively, there are more locations with degradations in the root zone soil moisture map. Generally, the root zone soil moisture skill improves with assimilation over the Central Plains, but degradations are observed at locations in the Southeast and Southwest. Note that the locations in the Central Plains with improvements in soil moisture generally correspond to agricultural and farmlands (Nebraska, lower Mississippi basin). These results suggest that the LAI assimilation helps in capturing the impact of vegetation changes in moisture states, introduced primarily from agriculture.

To investigate this further, time series of areaaveraged LAI from OL and DA integrations along with changes in root zone soil moisture over three specific crop (maize, soybean, and wheat from Fig. 1b) and grassland areas, which dominate the landscape over the Midwest and the Central Plains, are shown in Fig. 5. LAI assimilation has a larger impact over the maize and soybean areas compared to that over the wheat regions and grasslands. The seasonal peak in the LAI time series is generally in sync over the wheat and grasslands. The primary impact of assimilation over these areas is to adjust the amplitude of LAI. On the other hand, over the maize and soybean areas, the seasonality and the amplitude of LAI are both corrected by DA. The examination of the crop calendars of these crop types
(AMIS 2012) indicates that over the United States, the harvesting season of maize and soybean occurs in the fall and late summer months. This suggests that the OL simulation estimates an early peak in the LAI seasonality for these crops, which is corrected by the assimilation. The harvests of the winter wheat, on the other hand, occur during June and July, which is generally consistent with the peak seasonality of LAI estimated by the OL and DA introduces smaller phase corrections. Similarly, as the seasonality of vegetation over grasslands is primarily driven by natural variability, smaller changes to the phase of the LAI seasonality is introduced by DA.

As seen in the evaluations of other water/carbon variables in the following subsections, the adjustment of the vegetation seasonality leads to significant improvements over these crop areas. The adjustment of LAI also leads to seasonal patterns in the root zone soil moisture updates. Over the maize and soybean areas, the large changes (mostly reductions) in root zone soil moisture occur in the early fall time periods. The drier soil moisture features persist later into the fall and early winter time periods. Comparatively, over the wheat areas and grasslands, smaller reductions in root zone soil moisture are observed, because there are smaller corrections to the phase of LAI seasonality in these regions. 

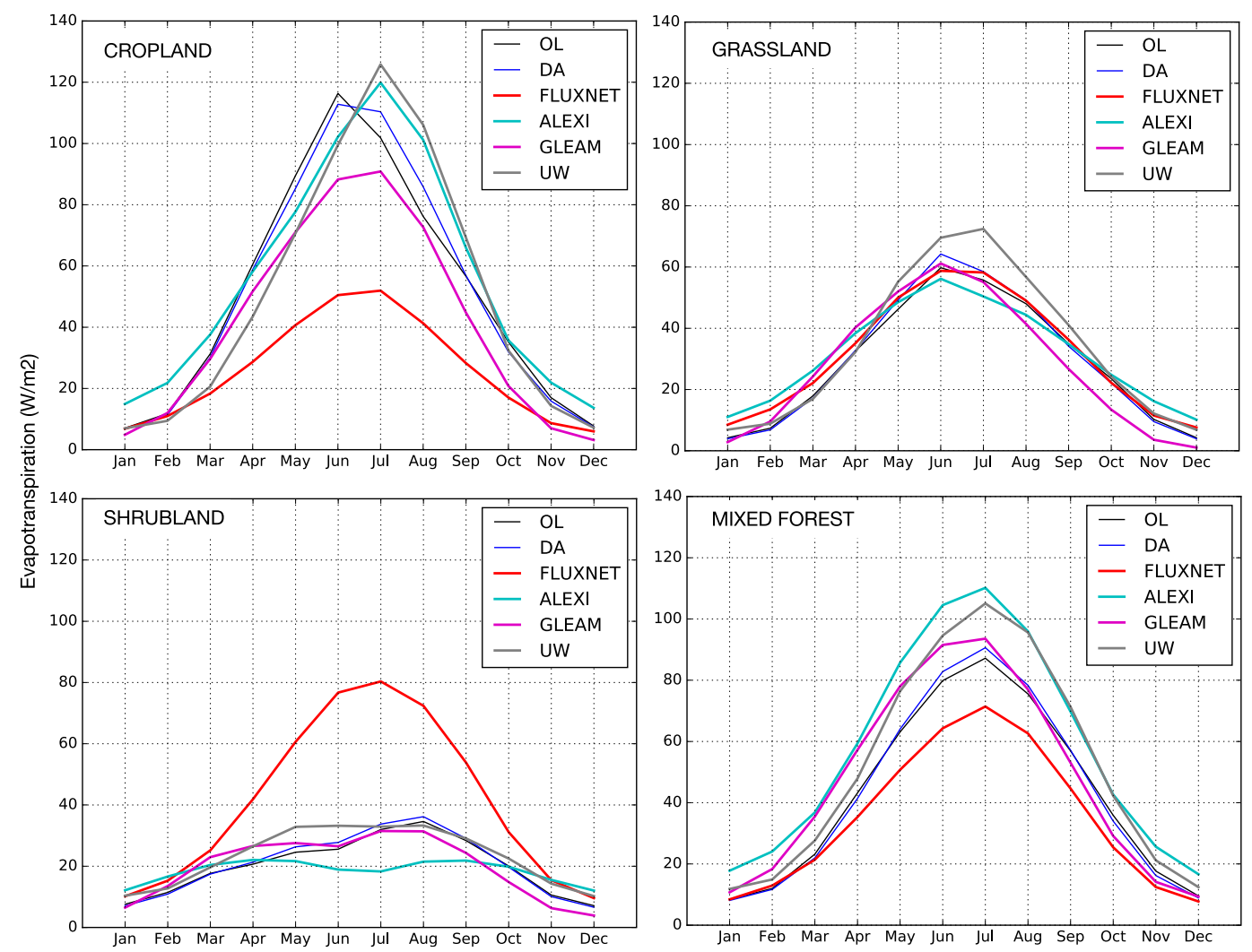

FIG. 7. Average seasonal cycle of evapotranspiration $\left(\mathrm{W} \mathrm{m}^{-2}\right)$ from the OL, DA, and the four reference datasets stratified by the four key dominant vegetation categories.

\section{b. Evapotranspiration}

The impact of LAI assimilation on modeled evapotranspiration fields is evaluated using four reference datasets: 1 ) the gridded $0.5^{\circ}$, monthly, FLUXNET multi-tree-ensemble (MTE) product (Jung et al. 2009), developed from upscaled eddy covariance tower measurements of evapotranspiration (available from 1982 to 2008$)$; 2) the $0.25^{\circ}$, daily Global Land Evaporation Amsterdam Model (GLEAM version 3.0a; Miralles et al. 2011) data, a primarily passive microwave remote sensing-based, Priestley Taylor evaporation model product (available during 1980-2014); 3) the 4-km, daily Atmosphere-Land Exchange Inverse (ALEXI; Anderson et al. 2007), a thermal-infrared based evapotranspiration product (available during 2001-15); and 4) the 5-km, monthly MODIS-based evapotranspiration product from University of Washington (UW; Tang et al. 2009; available during 2001-08). These products are derived from various sources with different methodologies and have random and bias errors of their own and are considered here for the purposes of intercomparison.

Maps of RMSE differences between evapotranspiration estimates from the OL and LAI DA integrations [computed as RMSE (OL) minus the RMSE (DA)] from the comparisons against the four reference datasets are shown in Fig. 6. The assimilation has a positive, statistically significant impact on the evapotranspiration estimates, with the RMSE decreasing in most parts of the domain in all four comparisons. In particular, there are systematic and consistent improvements over the Central Plains, lower Mississippi, central California valley, and parts of the Southeast. These spatial patterns are generally correlated with the cropland areas of Fig. 1. Specifically, in the comparisons with the ALEXI and UW data, the evapotranspiration improvements are primarily observed over the agricultural areas of maize and soybean, due to the changes to the LAI seasonality from DA (Fig. 5) over these areas. The use of fine-resolution thermal infrared remote sensing data in ALEXI and UW data has been shown to detect spatial variations of agricultural management impacts in prior studies (Tang et al. 2009; Hain et al. 2015).

The mean seasonal cycle of evapotranspiration from the OL and DA integrations (computing using all available years of each dataset during the 2000-17 time period) stratified by four dominant vegetation categories 
is shown in Fig. 7. The large differences in the evapotranspiration estimates across the reference dataset are obvious in this comparison. The variation in mean evapotranspiration across the vegetation types is generally small for FLUXNET MTE, whereas the other datasets show larger variations. The magnitude of evapotranspiration is larger over croplands and mixed forests and smaller over grasslands and shrublands, except for FLUXNET MTE. Over the croplands, the model OL has a phase lag in the peak of the seasonal means. In the reference datasets, the peak evapotranspiration is observed in July whereas the model runs show the peak in June. As noted above, this is likely due to the misrepresentation of the vegetation seasonality over agricultural areas. Assimilation helps to increase the evapotranspiration in the late summer months, consistent with the trends in the reference datasets. Over the other three vegetation categories, the mean evapotranspiration signals are more in-phase, suggesting that the natural variability is the dominant factor in the determination of evapotranspiration. It can be noted that the overall impact of DA is to increase the magnitude of evapotranspiration relative to the OL, particularly during the summer months.

\section{c. Carbon fluxes}

The impact of LAI assimilation on carbon fluxes is evaluated by comparing the GPP and the NEE estimates against reference data. While GPP represents the total fixation of carbon through photosynthesis, NEE refers to the GPP minus the carbon losses through respiration. Machine-learning-based upscaled estimates of GPP and NEE from the FLUXCOM project (Tramontana et al. 2016; Jung et al. 2017), available during the time period of 1980-2013, are used to evaluate the modeled GPP and NEE estimates.

Improvements in RMSE of GPP and NEE relative to the OL are shown in Fig. 8. The GPP estimates are consistently improved over most parts of the domain, except over a few areas such as parts of the Northwest and regions near the Great Lakes. More prominent improvements are seen in the lower Mississippi and Midwest regions. The pattern of improvement over the Midwest correlates well with the areas where maize is cultivated whereas the improvements in the lower Mississippi are primarily over the soybean areas (Fig. 1b). Comparatively, smaller improvements in GPP are observed over other crop areas such as wheat. The improvement map of NEE shows more mixed areas of improvements and degradations. While significant improvements in NEE estimates are obtained over the Central Plains and lower Mississippi through DA, assimilation also leads to degradations over most of the eastern United States. The areas of improvements in the
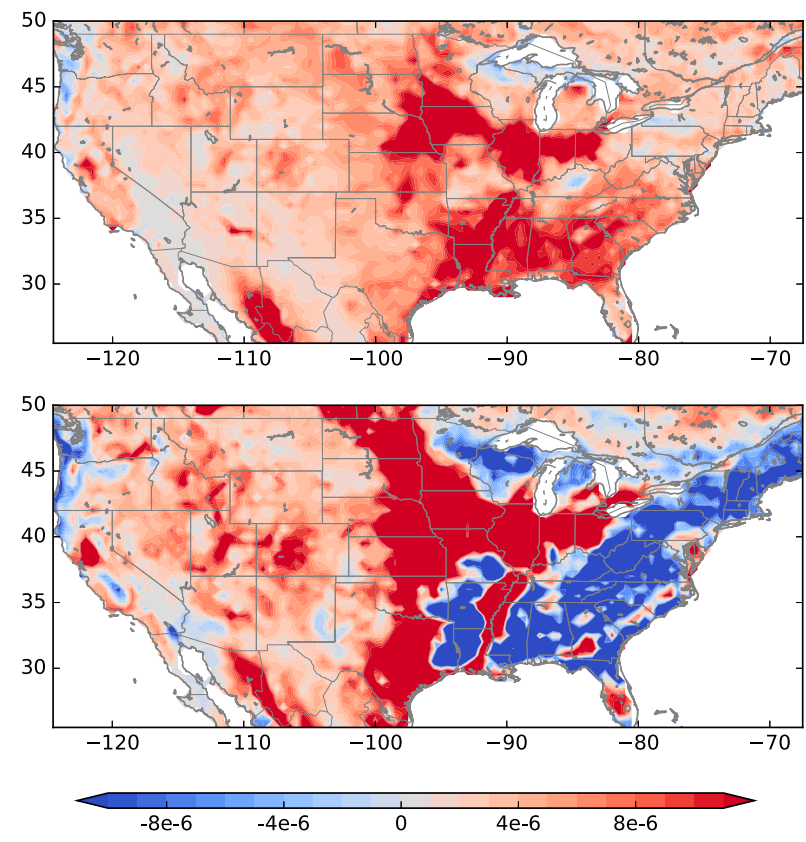

FIG. 8. Improvements in RMSE $\left(\mathrm{g} \mathrm{m}^{-2} \mathrm{~s}^{-1}\right)$ of (top) GPP and (bottom) NEE compared to the FLUXCOM data as the reference, during a time period of 2000-13. The warm and cool colors represent improvements and degradations from DA, respectively.

NEE fields are primarily correlated with the maize and soybean agricultural areas over the Midwest and lower Mississippi.

The average seasonal cycles of GPP and NEE from the model runs and the FLUXCOM data for croplands and grasslands are shown in Fig. 9. The model OL generally underestimates GPP, which is corrected by the assimilation. For NEE, the FLUXCOM estimates are positive, whereas the model OL produces negative values. The assimilation helps to correct these mismatches with the largest improvements obtained in late spring and early summer months. The assimilation also leads to increased biases in NEE in the fall and winter months. Figure 9 indicates that most of the improvements in GPP and NEE are primarily from the correction of biases in the model OL fields. Despite the improvements in NEE from DA, it is obvious that both OL and DA simulations systematically underestimate NEE during the growing season, suggesting that improvements to the model physics formulations may be necessary.

Solar induced fluorescence (SIF), part of the solar radiation absorbed by chlorophyll and re-emitted as fluorescence (Frankenberg et al. 2013; Frankenberg and Berry 2018), has been cited in several studies as a functional analog for GPP (Frankenberg et al. 2011; Guanter et al. 2012; Sun et al. 2018). Remote sensing retrievals of SIF are available from the Global Ozone Monitoring Experiment-2 (GOME-2) aboard the $M e t O p$ - $A$ satellite 

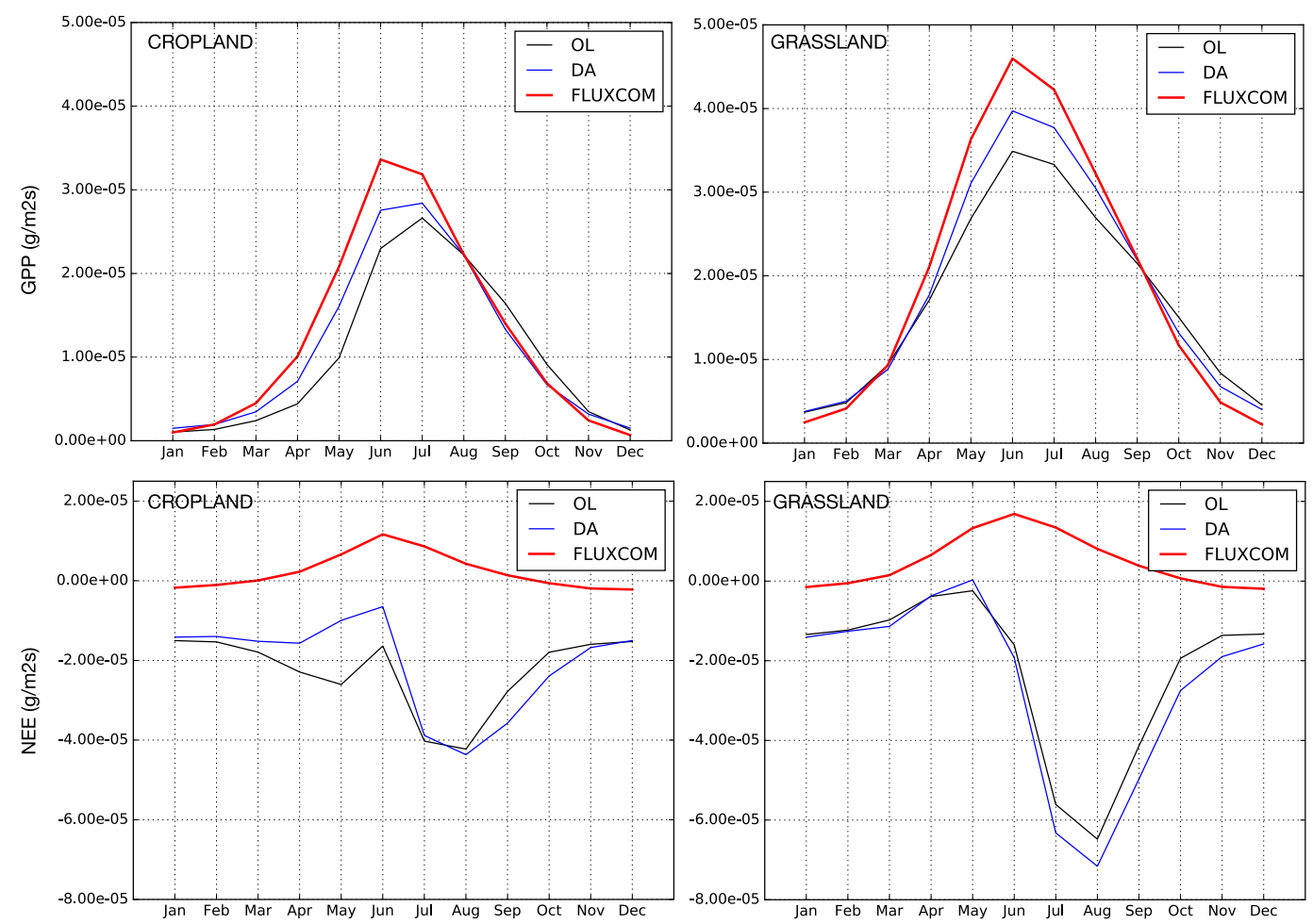

FIG. 9. Mean seasonal cycle of (top) GPP and (bottom) NEE $\left(\mathrm{g} \mathrm{m}^{-2} \mathrm{~s}^{-1}\right)$ stratified for cropland and grassland vegetation types during a time period of 2000-13.

(Joiner et al. 2014; Guanter et al. 2014). The correlation of the GPP estimates from OL and DA integrations is computed against the level-3, GOME-2 (version 27) retrievals, available during 2007-18, similar to the approach used in Leroux et al. (2018). Figure 10 shows a map of the improvements in the SIF-GPP correlation with the assimilation of LAI. The impact of assimilation is generally positive, with strong improvements observed in the southeastern United States, parts of the Midwest, southwest Mexico, and the central U.S. plains. The strong influence of the agricultural areas is also evident in Fig. 10, with statistically significant improvements in the SIF-GPP correlations observed over the maize and soybean croplands. This evaluation against the GOME-2 SIF retrievals provide further confirmation of the improvements in the modeled carbon fluxes from LAI assimilation, particularly over agricultural areas.

\section{d. Snow depth}

As noted earlier, vegetation changes on the land surface can have significant impacts on the snow evolution through the interception of snow by the canopy and modification of the surface albedo. These impacts are evaluated by comparing the modeled snow depth fields against three reference datasets: 1) the daily in situ measurements from the Global Historical Climate Network
(GHCN; Menne et al. 2012); 2) the daily, gridded snow depth analysis from the Canadian Meteorological Centre (CMC; Brown and Brasnett 2010) available at 25-km spatial resolution; and 3) the daily, gridded snow depth analysis from NOAA National Weather Service's National Operational Hydrologic Remote Sensing Center (NOHRSC) Snow Data Assimilation System (SNODAS; Barrett 2003) available at $1-\mathrm{km}$ spatial resolution. The GHCN data are available during the entire simulation

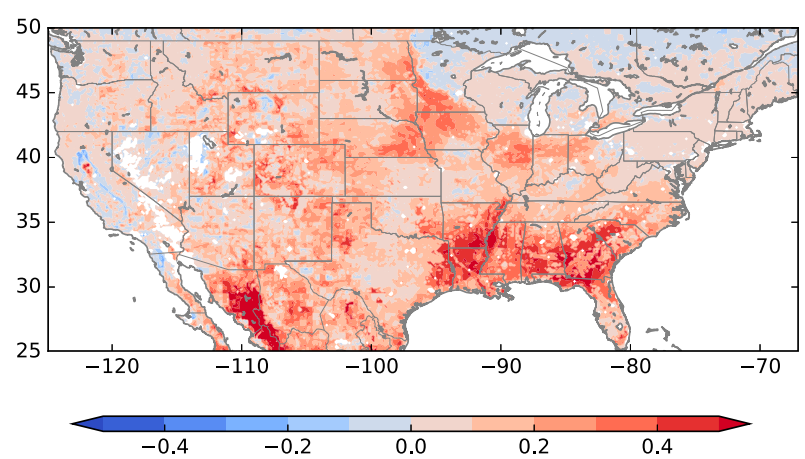

FIG. 10. Improvements in correlation of solar induced fluorescence data from GOME-2 with modeled GPP during 2007-17. The improvement map is expressed as $R(\mathrm{DA})$ minus $R(\mathrm{OL})$. The warm and cool colors represent improvements and degradations from DA, respectively. 

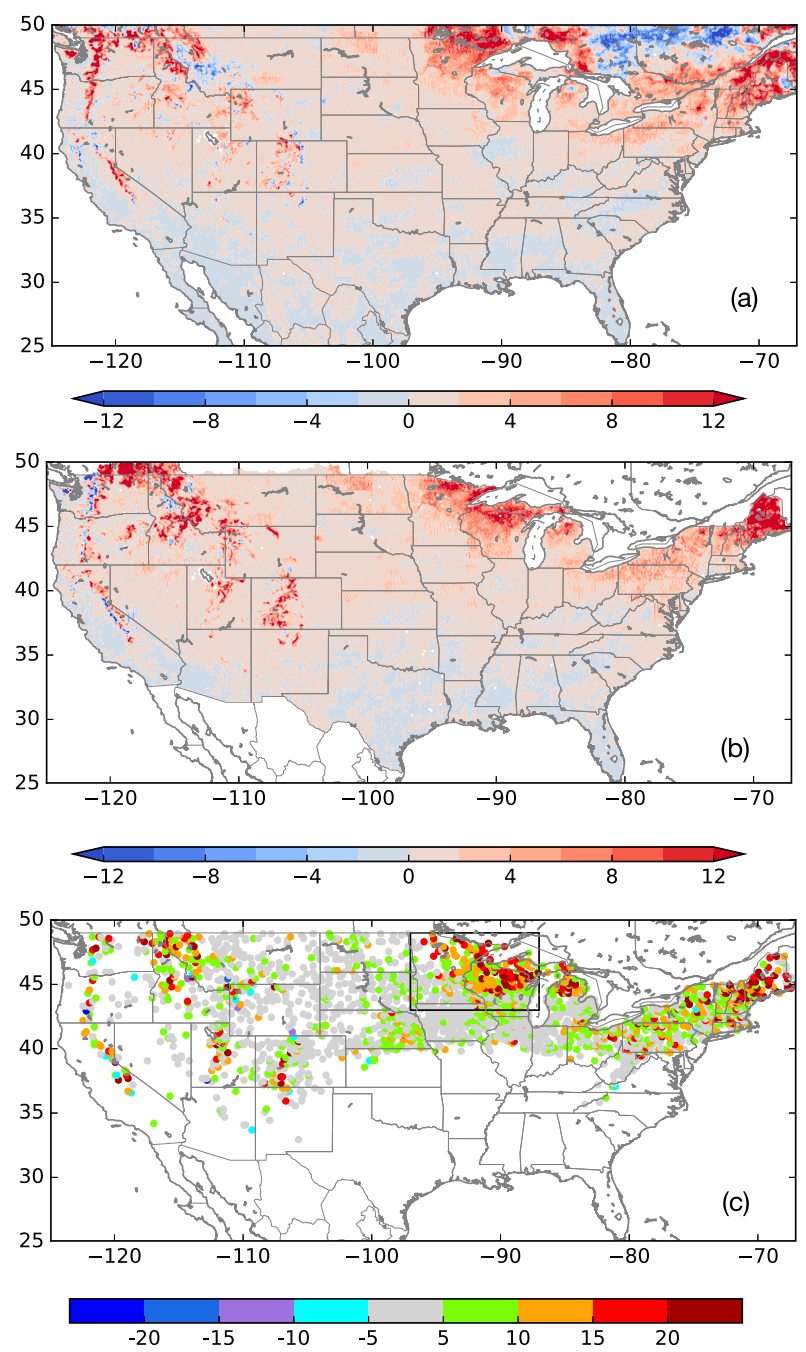

FIG. 11. Improvements in RMSE of snow depth ( $\mathrm{mm}$ ) compared to (a) CMC, (b) SNODAS, and (c) GHCN data as the reference. The time periods in the RMSE comparisons are 2000-17, 2003-17, and 2000-17 for CMC, SNODAS, and GHCN, respectively.

time period of 1979-2017. Based on the quality control procedures developed in previous studies (Kumar et al. 2014), a selected subset of the GHCN stations is used here. The CMC and SNODAS comparisons encompass a time period of 1998-2017 and 2003-17, respectively, based on the availability of these datasets.

The evaluation of snow depth fields against these datasets is shown in Fig. 11. The patterns in Fig. 11 indicate that, overall, LAI assimilation leads to reduced RMSE in the snow depth estimates. The improvements are most significant over the Northwest, areas near the Great Lakes, and Northeast. Notably, these patterns of improvements are consistent in all three comparisons. The improvements in the snow depth fields are primarily a result of the increase in snow mass due to the changes in LAI. A representative example time series over a region in the midwestern United States (shown by the marked rectangle in Fig. 11c) is shown in Fig. 12. To quantify the changes in snow depth fields from assimilation, Fig. 12 shows the differences in the areaaveraged snow depth from DA, CMC, SNODAS, and GHCN relative to the OL during the time period of 2008-12. The model OL has a significant dry bias in the snow depth fields compared to the reference datasets. This dry bias is improved by DA as the simulated snow depth increases with LAI assimilation. It can be observed that the increase in snow depth is closely tied to the increase in LAI (also shown as a difference in area-averaged LAI fields from DA and OL). Compared to the OL, the assimilation leads to a reduction in LAI during the fall and an increase during the winter, spring and summer months. The increase in LAI during the winter months contributes to increased snow in the assimilation integrations and is reflected as an improvement relative to the reference datasets. Despite these improvements, the snow depth estimates from the assimilation integrations still include significant biases, particularly with respect to SNODAS and GHCN. The spatial scale of these products is a factor in these biases as SNODAS is generated at $1-\mathrm{km}$ spatial resolution whereas the GHCN measurements are available at point scales.

\section{e. Terrestrial water storage}

TWS represents an integrated measure of the changes surface and subsurface water. Within Noah-MP, TWS is defined as the sum of the soil moisture, groundwater storage, snow, and canopy water content. The impact of LAI assimilation on TWS is evaluated by comparing against the TWS anomalies from the Gravity Recovery and Climate Experiment (GRACE; Tapley et al. 2004) satellite. The GRACE product available from the NASA Jet Propulsion Laboratory's Tellus website (https:/grace.jpl.nasa.gov/data/get-data/monthly-mass-gridsland/) is used in the comparisons. This product is available on a monthly basis on $1^{\circ}$ horizontal resolution grids (Landerer and Swenson 2012) from 2003 to 2017 and is based on the version RL05 spherical harmonics fields produced by the University of Texas Center for Space Research (CSR), Jet Propulsion Laboratory (JPL), and German Research Centre for Geosciences (GFZ).

An improvement map of the correlation of the TWS anomalies from the modeled fields and the GRACE solutions is shown in the top panel of Fig. 13. As before, the improvement map represents the difference between the correlations from DA and OL. The impact from DA on TWS anomalies is small, except over a few areas in the SGP, western Nebraska, and central California valley, where significant improvements are 


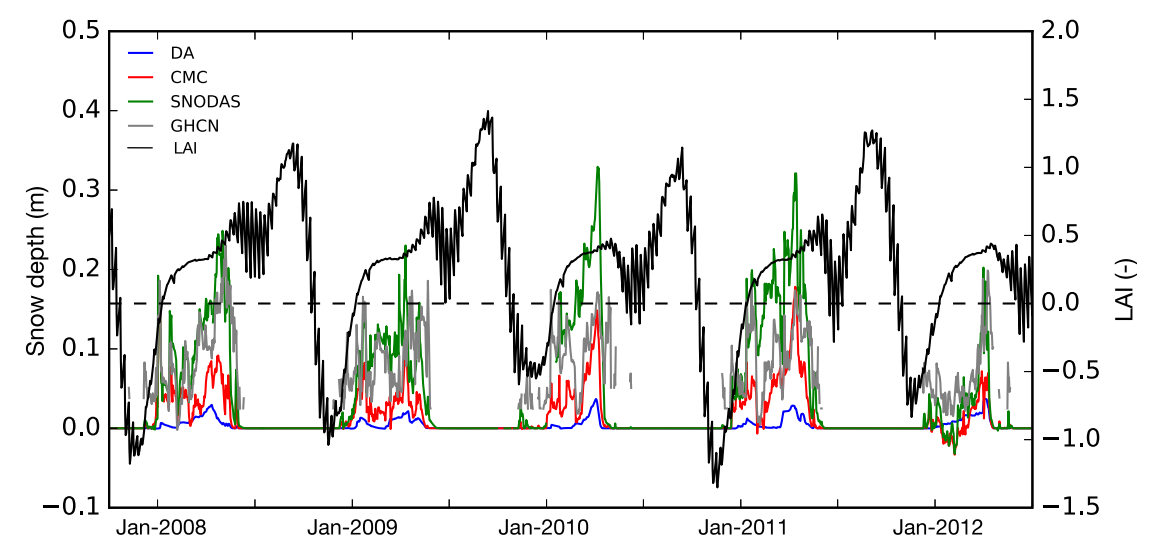

FIG. 12. Time series of differences in the area averaged snow depth (m) over the Midwest region (marked by the rectangle) in Fig. 11c from DA, CMC, SNODAS, and GHCN relative to the model OL during 2008-12. The right vertical axis shows a similar time series of differences in the area averaged LAI between the DA and OL integrations.

observed. A likely reason is that the assimilation improves the representation of agricultural areas and the related changes in increased water extraction and transpiration. This is confirmed by examining an area-averaged time series of TWS anomalies from the OL, DA, and GRACE over Nebraska and SGP (Fig. 13). Over the Nebraska region, the TWS anomalies from DA provide a better match to the GRACE data than that from the OL, except for the time period from 2009 to 2010. Similar patterns are seen over SGP, where the DA-based TWS anomalies are consistently closer to the GRACE estimates, except for a few time periods in 2007 and 2009. It is worth highlighting that the TWS anomaly improvements are not due to bias improvements in one direction alone. For example, over Nebraska, the TWS anomalies from the model OL have a wet bias in 2007-08 and a dry bias in 2010-13. Both these opposite biases are improved by LAI assimilation. Similar patterns can also be observed in the SGP time series where the dry and wet biases in TWS anomalies (during 2003-11 and 2012-13, respectively) are improved through assimilation.

\section{f. Streamflow}

Similar to TWS, streamflow represents an integrated measure of the terrestrial water balance. The daily streamflow data available from 1979 to 2017 from the U.S. Geological Survey over 572 hydrologic basins are used to evaluate the modeled streamflow estimates. As noted in prior studies (Kumar et al. 2014, 2016), these basins are identified as areas with minimal impact from reservoir operations.

Figure 14 shows a map of improvements in NashSutcliffe efficiency (NSE) and RMSE in streamflow DA expressed as a normalized information contribution (NIC). The NIC, NSE, and RMSE values are computed as

$$
\begin{aligned}
\mathrm{NIC}_{\mathrm{NSE}} & =\frac{\left(\mathrm{NSE}_{a}-\mathrm{NSE}_{o}\right)}{\left(1-\mathrm{NSE}_{o}\right)}, \quad \text { and } \\
\mathrm{NIC}_{\mathrm{RMSE}} & =\frac{\left(\mathrm{RMSE}_{o}-\mathrm{RMSE}_{a}\right)}{\left(\mathrm{RMSE}_{o}\right)},
\end{aligned}
$$

where subscripts $a$ and $o$ represent the LAI DA and OL, respectively. The NIC $_{\mathrm{NSE}}$ and NIC $_{\mathrm{RMSE}}$, therefore, represent a normalized measure of improvements in NSE and RMSE, respectively, from DA as a fraction of the maximum possible skill improvement.

Figure 14 indicates that LAI DA leads to improvements in streamflow skill over several river basins, including the upper Mississippi, Ohio, Columbia, upper Missouri, and South Atlantic. Comparatively, few locations show degradations, which are primarily limited to California and lower Colorado. Further, larger improvements in RMSE than those obtained in NSE are seen in Fig. 14. It is notable that improvements in the magnitude of streamflow (RMSE improvement map) are obtained in similar areas where the correlations also improve. Generally, LAI assimilation leads to drier streamflow conditions (Fig. 2) and these changes lead to more skillful streamflow estimates. These results confirm the indirect, but positive benefit from the assimilating LAI observations on streamflow estimates.

\section{g. Influence of assimilation frequency}

As noted earlier, the results presented above employ a DA configuration where daily interpolated estimates of LAI observations are used. This approach is used as it was found to be beneficial over that of assimilating LAI retrievals every 8 days. Table 1 provides a summary of the performance of the two DA configurations for different variables. It can be noted 

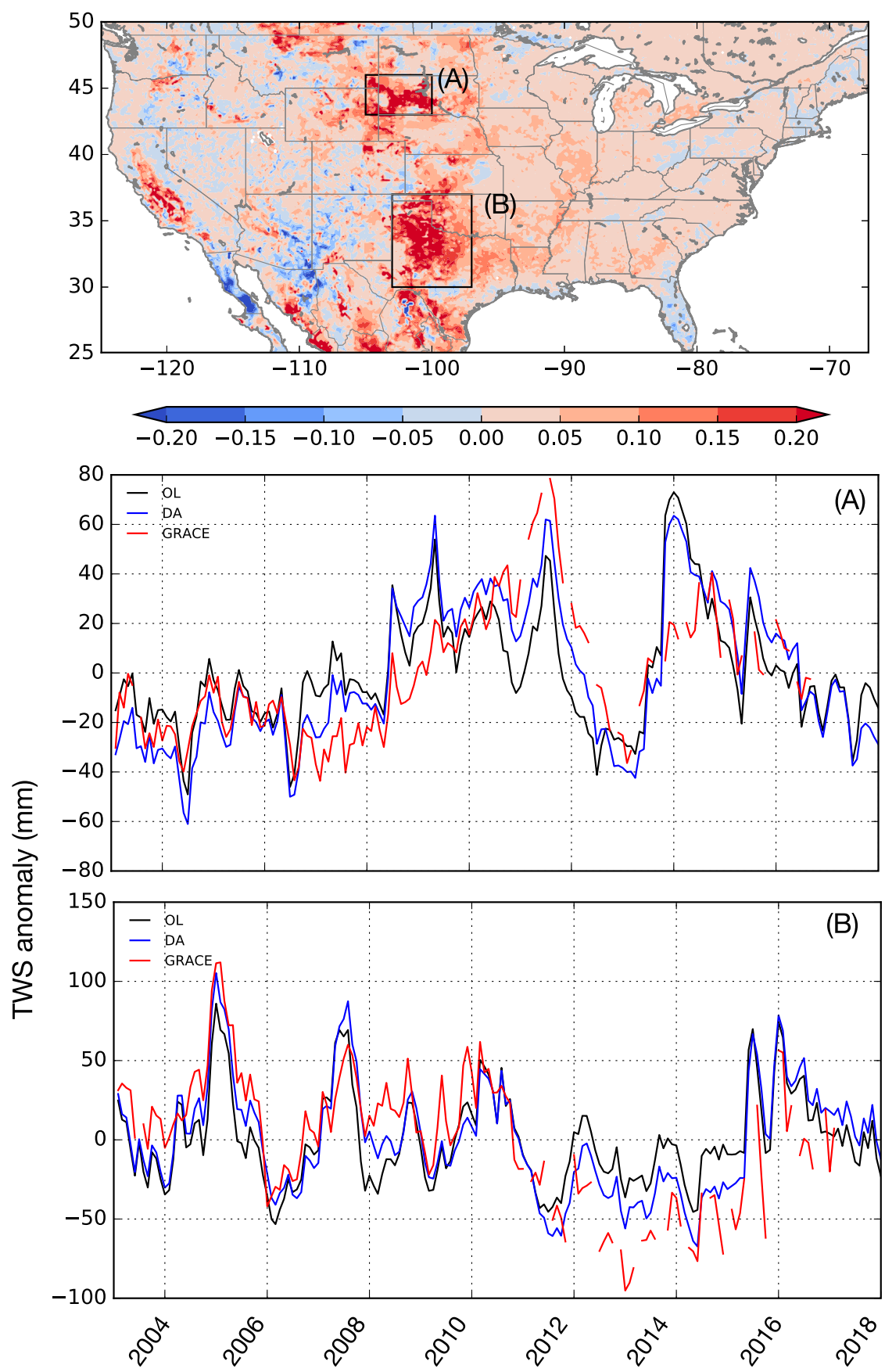

FIG. 13. (top) Improvements in correlations of TWS anomaly from the data assimilation integration during 2003-17 and (middle),(bottom) the area averaged time series of TWS anomaly $(\mathrm{mm})$ from OL and DA compared to the GRACE observations over the regions A and $\mathrm{B}$.

that in most comparisons, the daily DA configuration provides estimates that have better agreement with the reference measurements. The improvements in the anomaly $R$ of surface and root zone soil moisture are marginal, whereas in the ET comparisons, the 1-day DA configuration provides systematically lower domain-averaged RMSE estimates compared to those from the 8-day DA configuration. Similar trends are seen for GPP, Snow depth and Streamflow, where the 1-day DA configuration provides improved estimates relative to that from the 8-day DA configuration. For NEE, however, the 8-day configuration provides a lower RMSE than that from the 1-day 

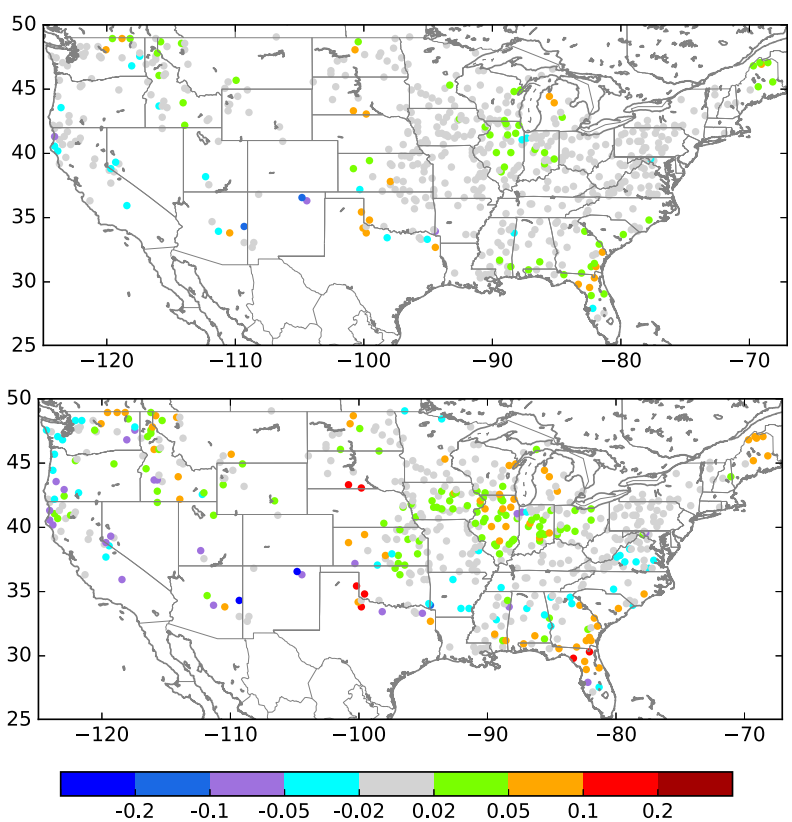

FIG. 14. Improvements in streamflow (top) NSE and (bottom) RMSE shown as NIC using the USGS daily streamflow observations as the reference.

configuration. The domain-averaged improvements seen in Table 1 suggest that the approach of employing temporally interpolated LAI values is reasonable.

\section{Summary}

Vegetation conditions on the land surface significantly impact the regional and global water budget and the variability of its components through the feedbacks and interactions between the biosphere and the terrestrial hydrosphere. Observations of vegetation conditions capture both anthropogenic and natural changes and disturbances on the land surface. Assimilation of such observations of vegetation conditions into LSMs, therefore, provides a way to incorporate the impact of vegetation changes in terrestrial hydrological and biosphere modeling.

This study presents the assimilation of remotely sensed LAI observations using the dynamic vegetation model of Noah-MP over the continental United States. The model integrations are conducted using the configuration of the NLDAS-2 environment, featuring high-quality meteorological input datasets. A 1-day EnKF algorithm is used to assimilate the MODIS reflectance-based LAI retrievals from the GLASS project. The model simulations are conducted during a time period of 2000-17. The impact of assimilating LAI on key water and carbon budget terms is evaluated by comparing against a large suite of available reference data products.

Overall, the assimilation has a positive and systematic impact on all water budget terms. When compared with in situ measurements, there are small, but systematic improvements in surface soil moisture estimates. The root zone soil moisture evaluations show mixed results, though improvements are observed over the Central Plains and the agricultural areas of the United States. Systematic improvements in the evapotranspiration fields are observed when compared to reference data products developed from tower, passive microwave, and visible/infrared measurements. Though there are significant biases across these products, the spatial patterns of improvements are consistent and are obtained primarily over agricultural areas. The assimilation of LAI estimates is also found to improve the snow depth estimates, which are primarily due to the correction of a dry bias in the snow mass estimates in the model OL. The assimilation generally leads to an

TABLE 1. Comparison of the domain-averaged skill metrics from the OL and DA configuration that uses the 8-day LAI values and the DA configuration that employs interpolated daily LAI values, for different variables. A dash (-) indicates dimensionless units.

\begin{tabular}{|c|c|c|c|c|c|}
\hline Variable & Reference data & Metric (units) & OL & DA (8 day) & DA (1 day) \\
\hline Surface soil moisture & ISMN & Anomaly $R(-)$ & 0.53 & 0.53 & 0.54 \\
\hline Root zone soil moisture & ISMN & Anomaly $R(-)$ & 0.48 & 0.48 & 0.49 \\
\hline \multirow[t]{4}{*}{ ET } & FLUXNET MTE & $\operatorname{RMSE}\left(\mathrm{W} \mathrm{m}^{-2}\right)$ & 15.1 & 14.1 & 13.9 \\
\hline & GLEAM & & 17.3 & 16.7 & 16.1 \\
\hline & ALEXI & & 32.2 & 31.1 & 30.9 \\
\hline & UW & & 23.1 & 21.5 & 21.4 \\
\hline GPP & FLUXCOM & $\operatorname{RMSE}\left(\mathrm{g} \mathrm{m}^{-2} \mathrm{~s}^{-1}\right)$ & $1.83 \times 10^{-4}$ & $1.41 \times 10^{-4}$ & $1.32 \times 10^{-4}$ \\
\hline NEE & FLUXCOM & $\operatorname{RMSE}\left(\mathrm{g} \mathrm{m}^{-2} \mathrm{~s}^{-1}\right)$ & $6.46 \times 10^{-4}$ & $5.72 \times 10^{-4}$ & $6.15 \times 10^{-4}$ \\
\hline \multirow[t]{3}{*}{ Snow depth } & $\mathrm{CMC}$ & $\operatorname{RMSE}(\mathrm{mm})$ & 64.9 & 64.0 & 63.8 \\
\hline & SNODAS & & 78.6 & 76.9 & 76.9 \\
\hline & $\mathrm{GHCN}$ & & 153.7 & 149.0 & 147.8 \\
\hline TWS & GRACE & Anomaly $R(-)$ & 0.45 & 0.47 & 0.48 \\
\hline Streamflow & USGS & $\operatorname{RMSE}\left(\mathrm{m}^{3} \mathrm{~s}^{-1}\right)$ & 23.2 & 22.9 & 22.7 \\
\hline
\end{tabular}


increase in LAI during the winter, spring, and summer months (relative to the OL) allowing for reduced snowmelt and improved snow simulations. The positive impact of assimilation on the water budget quantification is also confirmed through the evaluation of the TWS and streamflow fields, both indicating improvements through LAI DA.

In addition to the water budget, the impact of LAI assimilation on carbon fluxes is evaluated by comparing the modeled GPP and NEE fields against independent datasets. When compared to the machine learning-based, upscaled tower estimates, consistent improvements in the GPP estimates from assimilation are observed. Comparatively, the NEE results are more mixed, with degradations noted over the eastern United States. The spatial pattern of improvements in both GPP and NEE is found to correlate strongly with the cropland areas. The improvements in GPP through assimilation are also confirmed through an independent comparison against the GOME-2-based SIF retrievals. Similar significant improvements in the representation of vegetation cycles through the assimilation of LAI assimilation are reported in Albergel et al. (2018).

The comprehensive evaluation of the model integrations presented in the article indicates that the assimilation of LAI data is beneficial in simultaneously improving the key water and carbon budget components. Due to the use of high-quality NLDAS-2 meteorological inputs, the model OL (based on previous versions of Noah LSM) generally has high skill (Kumar et al. 2014,2019), particularly in capturing the impacts of natural variability. The fact that the incorporation of LAI observations further improves the NLDAS-2based OL implies that assimilation is helpful in developing better representation of vegetation changes on the land surface, which are not always driven by meteorological variability. As seen in the results, most significant improvements in the soil moisture, evapotranspiration, TWS, streamflow, GPP, and NEE fields are obtained over the agricultural areas in the Central Plains and Midwest, from corrections to the vegetation seasonality over crop areas.

Overall, assimilation leads to increasing the LAI in most parts of the domain, which leads to increased evapotranspiration, snow mass and GPP and reduced soil moisture and runoff. On the other hand, over the Midwest and parts of the Central Plains, evapotranspiration and GPP reduce and runoff and soil moisture increase, as assimilation leads to an overall reduction in LAI over these areas. It is worth noting that the assimilation improvements are obtained over these areas regardless of the bias changes introduced by LAI assimilation. Similar mixed changes in the biases are also observed temporally.
For example, when the TWS time series over the regions of the central plains are compared with GRACE, the assimilation provides both drying and wetting changes in the TWS, while providing a better match to the GRACE observations. These findings confirm that the benefits from LAI assimilation are not simply due to the correction of fortuitous biases in the model OL.

It can be noted that the assimilation configuration used in this manuscript only updates the leaf biomass variable. In reality, contributions of the stem, wood, and root mass also have significant roles in the determination of vegetation changes. Improved and discretized representation of variables such as rooting depth is needed for accurately capturing the soil moisture and vegetation biomass relationships. Model development efforts $\operatorname{cog}$ nizant of data assimilation requirements will be necessary for realizing the full potential and information content inherent in remote sensing measurements.

Acknowledgments. Funding for this work was provided by the NOAA's Climate Program Office (MAPP program). Computing was supported by the resources at the NASA Center for Climate Simulation. J. Borak was supported by NASA's National Climate AssessmentLand Data Assimilation project. The NLDAS-2 forcing data used in this effort were acquired as part of the activities of NASA's Science Mission Directorate, and are archived and distributed by the Goddard Earth Sciences (GES) Data and Information Services Center (DISC). The University of Maryland's Global Land Cover Facility (GLCF) and Beijing Normal University are thanked for their efforts with the GLASS LAI. We also thank Dr. Dev Niyogi and an anonymous reviewer for their constructive feedback during the review process.

\section{REFERENCES}

Albergel, C., and Coauthors, 2017: Sequential assimilation of satellite-derived vegetation and soil moisture products using SURFEX_v8.0: LDAS-Monde assessment over the EuroMediterranean area. Geosci. Model Dev., 10, 3889-3912, https://doi.org/10.5194/gmd-10-3889-2017.

— S. Munier, A. Bocher, B. Bonan, Y. Zheng, C. Draper, D. Leroux, and J.-C. Calvet, 2018: LDAS-Monde sequential assimilation of satellite derived observations applied to the contiguous US: An ERA-5 driven reanalysis of the land surface variables. Remote Sens., 10, 1627, https://doi.org/10.3390/rs10101627.

AMIS, 2012: AMIS crop calendar. Viale delle Terme di Caracalla, Rome, Italy, Agricultural Market Information System, Food and Agriculture Organization of the United Nations, www.amis-outlook.org.

Anderson, M., J. Norman, J. Mecikalski, J. Otkin, and W. Kustas, 2007: A climatological study of evapotranspiration and moisture stress across the continental U.S. based on thermal remote sensing: I. Model formulation. J. Geophys. Res., 112, D10117, https://doi.org/10.1029/2006JD007506. 
Ball, J., I. Woodrow, and J. Berry, 1987: A model predicting stomatal conductance and its contribution to the control of photosynthesis under different environmental conditions. Progress in Photosynthesis Research, Vol. 4, J. Biggins, Ed., Springer, 221224, https://doi.org/10.1007/978-94-017-0519-6_48.

Barbu, A., J.-C. Calvet, J.-F. Mahfouf, C. Albergel, and S. Lafont, 2011: Assimilation of soil wetness index and leaf area index into the ISBA-A-gs land surface model: Grassland case study. Biogeosciences, 8, 1971, https://doi.org/10.5194/bg-8-1971-2011.

,,--- , and S. Lafont, 2014: Integrating ASCAT surface soil moisture and GEOV1 leaf area index into the SURFEX modelling platform: A land data assimilation application over France. Hydrol. Earth Syst. Sci., 18, 173-192, https://doi.org/ 10.5194/hess-18-173-2014.

Barrett, A., 2003: National Operational Hydrologic Remote Sensing Center Snow Data Assimilation System (SNODAS) products at NSIDC. NSIDC Special Rep. 11, 19 pp., https://nsidc.org/sites/ nsidc.org/files/files/nsidc_special_report_11.pdf.

Brown, R., and B. Brasnett, 2010: Canadian Meteorological Centre (CMC) daily snow depth analysis data, version 1. NSIDC DAAC, accessed January 2019, https://doi.org/10.5067/ W9FOYWH0EQZ3.

Cowling, S., and C. Field, 2003: Environmental control of leaf area production: Implications for vegetation and land-surface modeling. Global Biogeochem. Cycles, 17, 1007, https://doi.org/ 10.1029/2002GB001915.

Crow, W. T., S. V. Kumar, and J. D. Bolten, 2012: On the utility of land surface models for agricultural drought monitoring. Hydrol. Earth Syst. Sci., 16, 3451-3460, https://doi.org/10.5194/ hess-16-3451-2012.

De Lannoy, G., R. Reichle, K. Arsenault, P. Houser, S. Kumar, N. Verhoest, and V. Pauwels, 2012: Multiscale assimilation of Advanced Microwave Scanning Radiometer-EOS snow water equivalent and Moderate Resolution Imaging Spectroradiometer snow cover fraction observations in northern Colorado. Water Resour. Res., 48, W01522, https://doi.org/10.1029/ 2011WR010588.

Dente, L., G. Satalino, F. Mattia, and M. Rinaldi, 2008: Assimilation of leaf area index derived from ASAR and MERIS data into CERES-Wheat model to map wheat yield. Remote Sens. Environ., 112, 1395-1407, https://doi.org/10.1016/j.rse.2007.05.023.

Dickinson, R. E., M. Shaikh, R. Bryant, and L. Graumlich, 1998: Interactive canopies for a climate model. J. Climate, 11, 2823-2836, https://doi.org/10.1175/1520-0442(1998)011<2823: ICFACM $>2.0 . \mathrm{CO} ; 2$.

Dorigo, W., P. van Oevelen, W. Wagner, S. Mecklenburg, A. Robock, and T. Jackson, 2011: A new international network for soil moisture data. Eos, Trans. Amer. Geophys. Union, 92 , 141-142, https://doi.org/10.1029/2011EO170001.

Dziubanski, D. J., and K. J. Franz, 2016: Assimilation of AMSR-E snow water equivalent data in a spatially-lumped snow model. J. Hydrol., 540, 26-39, https://doi.org/10.1016/ j.jhydrol.2016.05.046.

Ek, M., and Coauthors, 2017: Next phase of the NCEP unified land data assimilation system (NULDAS): Vision, requirements and implementation. NASA GSFC, 17 pp., https://ldas.gsfc.nasa.gov/sites/ default/files/ldas/nldas/White_Paper_for_Next_Phase_ LDAS_final.pdf.

Essery, R., J. Pomeroy, J. Parviainen, and P. Storck, 2003: Sublimation of snow from coniferous forests in a climate model. J. Climate, 16, 1855-1864, https://doi.org/10.1175/15200442(2003)016<1855:SOSFCF $>2.0$.CO;2.
Fang, H., and Coauthors, 2013: Characterization and intercomparison of global moderate resolution leaf area index (LAI) products: Analysis of climatologies and theoretical uncertainties. J. Geophys. Res. Biogeosci., 118, 529-548, https:// doi.org/10.1002/jgrg.20051.

Frankenberg, C., and J. Berry, 2018: Solar induced chlorophyll fluorescence: Origins, relation to photosynthesis and retrieval. Terrestrial Ecosystems, J. M. Chen, Ed., Vol. 3, Comprehensive Remote Sensing, Elsevier, 143-162, https://doi.org/ 10.1016/B978-0-12-409548-9.10632-3.

, and Coauthors, 2011: New global observations of the terrestrial carbon cycle from GOSAT: Patterns of plant fluorescence with gross primary productivity. Geophys. Res. Lett., 38, L17706, https://doi.org/10.1029/2011GL048738.

_ J. Berry, L. Guanter, and J. Joiner, 2013: Remote sensing of terrestrial chlorophyll fluorescence from space. SPIE Newsroom, https://doi.org/10.1117/2.1201302.004725.

Garcia, M., M. Ozdogan, and P. A. Townsend, 2014: Impacts of forest harvest on cold season land surface conditions and land-atmosphere interactions in northern great lakes states. J. Adv. Model. Earth Syst., 6, 923-937, https://doi.org/10.1002/ 2014MS000317.

Getirana, A., A. Boone, D. Yamazaki, B. Decharme, F. Papa, and N. Mognard, 2012: The Hydrological Modeling and Analysis Platform (HyMAP): Evaluation in the Amazon basin. J. Hydrometeor., 13, 1641-1665, https://doi.org/10.1175/JHM-D-12-021.1.

Guanter, L., C. Frankenberg, A. Dudhia, P. Lewis, J. Gomez-Dans, A. Kuze, H. Suto, and R. Grainger, 2012: Retrieval and global assessment of terrestrial chlorophyll fluorescence from GOSAT space measurements. Remote Sens. Environ., 121, 236-251, https:// doi.org/10.1016/j.rse.2012.02.006.

_- and Coauthors, 2014: Global and time-resolved monitoring of crop photosynthesis with chlorophyll fluorescence. Proc. Natl. Acad. Sci. USA, 111, E1327-E1333, https://doi.org/10.1073/ pnas. 1320008111.

Hain, C. R., W. T. Crow, M. C. Anderson, and M. T. Yilmaz, 2015: Diagnosing neglected soil moisture source-sink processes via a thermal infrared-based two-source energy balance model. J. Hydrometeor., 16, 1070-1086, https://doi.org/10.1175/ JHM-D-14-0017.1.

Hansen, M., R. DeFries, J. Townshend, and R. Sohlberg, 2000: Global land cover classification at $1 \mathrm{~km}$ spatial resolution using a classification tree approach. Int. J. Remote Sens., 21, 1331-1364, https://doi.org/10.1080/014311600210209.

Huang, Y., S. Gerber, T. Huang, and J. W. Lichstein, 2016: Evaluating the drought response of CMIP5 models using global gross primary productivity, leaf area, precipitation, and soil moisture data. Global Biogeochem. Cycles, 30, 1827-1846, https://doi.org/10.1002/2016GB005480.

Ines, A. V., N. N. Das, J. W. Hansen, and E. G. Njoku, 2013: Assimilation of remotely sensed soil moisture and vegetation with a crop simulation model for maize yield prediction. Remote Sens. Environ., 138, 149-164, https://doi.org/10.1016/j.rse.2013.07.018.

Jasechko, S., Z. Sharp, J. Gibson, S. Birks, Y. Yi, and P. Fawcett, 2013: Terrestrial water fluxes dominated by transpiration. Nature, 496, 347-350, https://doi.org/10.1038/nature11983.

Jin, X., L. Kumar, Z. Li, H. Feng, X. Xu, G. Yang, and J. Wang, 2018: A review of data assimilation of remote sensing and crop models. Eur. J. Agron., 92, 141-152, https://doi.org/10.1016/ j.eja.2017.11.002.

Joiner, J., and Coauthors, 2014: The seasonal cycle of satellite chlorophyll fluorescence observations and its relationship to vegetation phenology and ecosystem atmosphere carbon 
exchange. Remote Sens. Environ., 152, 375-391, https:// doi.org/10.1016/j.rse.2014.06.022.

Jung, M., M. Reichstein, and A. Bondeau, 2009: Towards a global empirical upscaling of FLUXNET eddy covariance observations: Validation of a model tree ensemble approach using a biosphere model. Biogeosciences, 6, 2001-2003, https://doi.org/ 10.5194/bg-6-2001-2009.

, and Coauthors, 2017: Compensatory water effects link yearly global land $\mathrm{CO}_{2}$ sink changes to temperature. Nature, 541, 516-520, https://doi.org/10.1038/nature20780.

Kumar, L., and O. Mutanga, 2017: Remote sensing of aboveground biomass. Remote Sens., 9, 935, https://doi.org/10.3390/ rs9090935.

Kumar, S., and Coauthors, 2006: Land Information System: An interoperable framework for high resolution land surface modeling. Environ. Modell. Software, 21, 1402-1415, https:// doi.org/10.1016/j.envsoft.2005.07.004.

, C. Peters-Lidard, J. Santanello, K. Harrison, Y. Liu, and M. Shaw, 2012: Land surface Verification Toolkit (LVT)—A generalized framework for land surface model evaluation. Geosci. Model Dev., 5, 869-886, https://doi.org/10.5194/gmd-5869-2012.

_- and Coauthors, 2014: Assimilation of remotely sensed soil moisture and snow depth retrievals for drought estimation. J. Hydrometeor., 15, 2446-2469, https://doi.org/10.1175/JHMD-13-0132.1.

—, C. Peters-Lidard, K. Arsenault, A. Getirana, D. Mocko, and Y. Liu, 2015: Quantifying the added value of snow cover area observations in passive microwave snow depth data assimilation. J. Hydrometeor., 16, 1736-1741, https://doi.org/10.1175/ JHM-D-15-0021.1.

— , and Coauthors, 2016: Assimilation of gridded GRACE terrestrial water storage estimates in the North American Land Data Assimilation System. J. Hydrometeor., 17, 1951-1972, https://doi.org/10.1175/JHM-D-15-0157.1.

—, M. Jasinski, D. Mocko, M. Rodell, J. Borak, B. Li, H. Beudoing, and C. Peters-Lidard, 2019: NCA-LDAS land analysis: Development and performance of a multisensor, multivariate land data assimilation system for the National Climate Assessment. J. Hydrometeor., https://doi.org/10.1175/ JHM-D-17-0125.1, in press.

Landerer, F., and S. Swenson, 2012: Accuracy of scaled GRACE terrestrial water storage estimates. Water Resour. Res., 48, W04531, https://doi.org/10.1029/2011WR011453.

Leff, B., N. Ramankutty, and J. Foley, 2004: Geographic distribution of major crops across the world. Global Biogeochem. Cycles, 18, GB1009, https://doi.org/10.1029/2003GB002108.

Leroux, D., J.-C. Calvet, S. Munier, and C. Albergel, 2018: Using satellite-derived vegetation products to evaluate LDASMonde over the Euro-Mediterranean area. Remote Sens., 10, 1199, https://doi.org/10.3390/rs10081199.

Liang, S., and Coauthors, 2013: A long-term Global LAnd Surface Satellite (GLASS) data-set for environmental studies. Int. J. Digit. Earth, 6, 5-33, https://doi.org/10.1080/ 17538947.2013.805262.

Liao, Y., Y. Gai, W. Fan, X. Xu, B. Yan, and Y. Liu, 2012: Validation methods of LAI products based on scaling effect. 2012 IEEE Int. Geoscience and Remote Sensing Symp., Munich, Germany, IEEE, 1692-1694, https://doi.org/10.1109/ IGARSS.2012.6351200.

Liu, H., J. T. Randerson, J. Lindfors, and F. S. Chapin, 2005: Changes in the surface energy budget after fire in boreal ecosystems of interior Alaska: An annual perspective.
J. Geophys. Res., 110, D13101, https://doi.org/10.1029/ 2004JD005158.

Liu, Q., and Coauthors, 2011: The contributions of precipitation and soil moisture observations to the skill of soil moisture estimates in a land data assimilation system. J. Hydrometeor., 12, 750-765, https://doi.org/10.1175/JHM-D-10-05000.1.

Liu, X., F. Chen, M. Barlage, G. Zhou, and D. Niyogi, 2016: NoahMP-Crop: Introducing dynamic crop growth in the Noah-MP land surface model. J. Geophys. Res. Atmos., 121, $13953-$ 13 972, https://doi.org/10.1002/2016JD025597.

Liu, Y., C. Peters-Lidard, S. Kumar, K. Arsenault, and D. Mocko, 2015: Blending satellite-based snow depth products with insitu observations for streamflow predictions in the Upper Colorado River Basin. Water Resour. Res., 51, 1182-1202, https://doi.org/10.1002/2014WR016606.

McDermid, S. S., L. O. Mearns, and A. C. Ruane, 2017: Representing agriculture in Earth system models: Approaches and priorities for development. J. Adv. Model. Earth Syst., 9, 22302265, https://doi.org/10.1002/2016MS000749.

Menne, M. J., I. Durre, R. Vose, B. E. Gleason, and T. G. Houston, 2012: An overview of the global historical climatology network-daily database. J. Atmos. Oceanic Technol., 29, 897910, https://doi.org/10.1175/JTECH-D-11-00103.1.

Miralles, D., T. Holmes, R. de Jeu, J. Gash, A. Meesters, and A. Dolman, 2011: Global land-surface evaporation estimated from satellite-based observations. Hydrol. Earth Syst. Sci., 15, 453-469, https://doi.org/10.5194/hess-15-453-2011.

Mitchell, K., and Coauthors, 2004: The multi-institution North American Land Data Assimilation System (NLDAS): Utilizing multiple GCIP products and partners in a continental distributed hydrological modeling system. J. Geophys. Res., 109, D07S90, https://doi.org/10.1029/2003JD003823.

Munier, S., D. Carrer, C. Planque, F. Camacho, C. Albergel, and J.-C. Calvet, 2018: Satellite leaf area index: Global scale analysis of the tendencies per vegetation type over the last 17 years. Remote Sens., 10, 424, https://doi.org/10.3390/rs10030424.

Myneni, R., and Coauthors, 2002: Global products of vegetation leaf area and fraction absorbed PAR from year one of MODIS data. Remote Sens. Environ., 83, 214-231, https://doi.org/ 10.1016/S0034-4257(02)00074-3.

_- Y. Knyazikhin, and N. Shabanov, 2011: Leaf area index and fraction of absorbed PAR products from Terra and Aqua MODIS sensors: Analysis, validation and refinement. Land Remote Sensing and Global Environmental Change, Remote Sensing and Digital Image Processing, Vol. 11, Springer, 603 633, https://doi.org/10.1007/978-1-4419-6749-7_27.

Niu, G.-Y., and Z.-L. Yang, 2004: Effects of vegetation canopy processes on snow surface energy and mass balances. J. Geophys. Res., 109, D23111, https://doi.org/10.1029/ 2004JD004884.

,,-- R. E. Dickinson, L. E. Gulden, and H. Su, 2007: Development of a simple groundwater model for use in climate models and evaluation with Gravity Recovery and Climate Experiment data. J. Geophys. Res., 112, D07103, https:// doi.org/10.1029/2006JD007522.

_ model with multiparameterization options (Noah-MP): 1. Model description and evaluation with local-scale measurements. J. Geophys. Res., 116, D12109, https://doi.org/10.1029/ 2010JD015139.

Niyogi, D., K. Alapaty, S. Raman, and F. Chen, 2009: Development and evaluation of a coupled photosynthesis-based gas exchange evapotranspiration model (GEM) for mesoscale 
weather forecasting applications. J. Appl. Meteor. Climatol., 48, 349-368, https://doi.org/10.1175/2008JAMC1662.1.

Peters-Lidard, C. D., and Coauthors, 2007: High-performance Earth System modeling with NASA/GSFC's Land Information System. Innov. Syst. Software Eng., 3, 157-165, https:// doi.org/10.1007/s11334-007-0028-x.

Peters-Lidard, C., S. V. Kumar, D. M. Mocko, and Y. Tian, 2011: Estimating evapotranspiration with land data assimilation systems. Hydrol. Processes, 25, 3979-3992, https://doi.org/ 10.1002/hyp.8387.

Pitman, A. J., 2003: The evolution of, and revolution in, land surface schemes designed for climate models. Int. J. Climatol., 23, 479-510, https://doi.org/10.1002/joc.893.

Reichle, R., D. McLaughlin, and D. Entekhabi, 2002: Hydrologic data assimilation with the ensemble Kalman filter. Mon. Wea. Rev., 130, 103-114, https://doi.org/10.1175/1520-0493(2002) 130<0103:HDAWTE $>2.0 . \mathrm{CO} ; 2$.

—, R. Koster, P. Liu, S. P. P. Mahanama, E. Njoku, and M. Owe, 2007: Comparison and assimilation of global soil moisture retrievals from the Advanced Microwave Scanning Radiometer for the Earth Observing System (AMSRE) and the Scanning Multichannel Microwave Radiometer (SMMR). J. Geophys. Res., 112, D09108, https://doi.org/10.1029/ 2006JD008033.

— , S. Kumar, S. Mahanama, R. Koster, and Q. Liu, 2010: Assimilation of satellite-derived skin temperature observations into land surface models. J. Hydrometeor., 11, 1103-1122, https://doi.org/10.1175/2010JHM1262.1.

Rudiger, C., C. Albergel, J.-F. Mahfouf, J.-C. Calvet, and J. Walker, 2010: Evaluation of Jacobians for leaf area index data assimilation with an extended Kalman filter. J. Geophys. Res., 115, D09111, https://doi.org/10.1029/2009JD012912.

Sabater, J., C. Rudiger, J.-C. Calvet, N. Fritz, L. Jarlan, and Y. Kerr, 2008: Joint assimilation of surface soil moisture and LAI observations into a land surface model. Agric. Forest Meteor., 148, 1362-1373, https://doi.org/10.1016/ j.agrformet.2008.04.003.

Sato, H., A. Ito, A. Ito, T. Ise, and E. Kato, 2015: Current status and future of land surface models. Soil Sci. Plant Nutr., 61, 34-47, https://doi.org/10.1080/00380768.2014.917593.

Schlesinger, W. H., and S. Jasechko, 2014: Transpiration in the global water cycle. Agric. For. Meteor., 189-190, 115-117, https://doi.org/10.1016/j.agrformet.2014.01.011.

Sellers, P. J., and Coauthors, 1997: Modeling the exchanges of energy, water, and carbon between continents and the atmosphere. Science, 275, 502-509, https://doi.org/10.1126/ science.275.5299.502.

Sun, Y., C. Frankenberg, M. Jung, J. Joiner, L. Guanter, P. Kohler, and T. Magney, 2018: Overview of Solar-Induced chlorophyll Fluorescence (SIF) from the Orbiting Carbon Observatory-2: Retrieval, cross-mission comparison, and global monitoring for GPP. Remote Sens. Environ., 209, 808-823, https://doi.org/ 10.1016/j.rse.2018.02.016.

Tang, Q., S. Peterson, R. Cuenca, Y. Hagimoto, and D. Lettenmaier, 2009: Satellite-based near-real-time estimation of irrigated crop water consumption. J. Geophys. Res., 114, D05114, https:// doi.org/10.1029/2008JD010854.

Tapley, B., S. Bettadpur, M. Watkins, and C. Reigber, 2004: The Gravity Recovery and Climate Experiment: Mission overview and early results. Geophys. Res. Lett., 31, L09607, https:// doi.org/10.1029/2004GL019920.

Tramontana, G., and Coauthors, 2016: Predicting carbon dioxide and energy fluxes across global FLUXNET sites with regression algorithms. Biogeosciences, 13, 4291-4313, https://doi.org/10.5194/bg-13-4291-2016.

Tucker, C. J., J. E. Pinzon, M. E. Brown, D. A. Slayback, E. W. Pak, R. Mahoney, E. F. Vermote, and N. E. Saleous, 2005: An extended AVHRR 8-km NDVI dataset compatible with MODIS and SPOT vegetation NDVI data. Int. J. Remote Sens., 26, 44854498, https://doi.org/10.1080/01431160500168686.

Wang, H., Y. Zhu, W. Li, W. Cao, and Y. Tian, 2014: Integrating remotely sensed leaf area index and leaf nitrogen accumulation with RiceGrow model based on particle swarm optimization algorithm for rice grain yield assessment. J. Appl. Remote Sens., 8, 083674, https://doi.org/10.1117/1.JRS.8.083674.

Xia, Y., M. Ek, H. Wei, and J. Meng, 2012a: Comparative analysis of relationships between NLDAS-2 forcings and model outputs. Hydrol. Processes, 26, 467-474, https://doi.org/10.1002/ hyp. 8240 .

— flux analysis and validation for the North American Land Data Assimilation System project phase 2 (NLDAS-2): 1. Intercomparison and application of model products. J. Geophys. Res., 117 D03110, https://doi.org/10.1029/ 2011JD016048.

Xiao, Z., S. Liang, J. Wang, P. Chen, X. Yin, L. Zhang, and J. Song, 2014: Use of general regression neural networks for generating the GLASS leaf area index product from time-series MODIS surface reflectance. IEEE Trans. Geosci. Remote Sens., 52, 209-223, https://doi.org/10.1109/TGRS.2013.2237780.

,,,-- Y Y. Xiang, X. Zhao, and J. Song, 2016: Long-timeseries global land surface satellite leaf area index product derived from MODIS and AVHRR surface reflectance. IEEE Trans. Geosci. Remote Sens., 54, 5301-5318, https://doi.org/ 10.1109/TGRS.2016.2560522.

Xie, Y., P. Wang, X. Bai, J. Khan, S. Zhang, L. Li, and L. Wang, 2017: Assimilation of the leaf area index and vegetation temperature condition index for winter wheat yield estimation using Landsat imagery and the CERES-Wheat model. Agric. For. Meteor., 246, 194-206, https://doi.org/10.1016/ j.agrformet.2017.06.015.

Yang, Z.-L., and Coauthors, 2011: The community Noah land surface model with multiparameterization options (Noah-MP): 2. Evaluation over global river basins. J. Geophys. Res., 116, D12110, https://doi.org/10.1029/2010JD015140.

Zaitchik, B. F., and M. Rodell, 2009: Forward-looking assimilation of MODIS-derived snow-covered area into a land surface model. J. Hydrometeor., 10, 130-148, https://doi.org/10.1175/ 2008JHM1042.1.

Zhang, Y.-F., T. J. Hoar, Z.-L. Yang, J. L. Anderson, A. M. Toure, and M. Rodell, 2014: Assimilation of MODIS snow cover through the Data Assimilation Research Testbed and the Community Land Model version 4. J. Geophys. Res. Atmos., 119, 7091-7103, https://doi.org/10.1002/2013JD021329.

Zheng, G., and L. Moskal, 2009: Retrieving leaf area index (LAI) using remote sensing: Theories, methods and sensors. Sensors, 9, 2719-2745, https://doi.org/10.3390/s90402719.

Zhu, Z., and Coauthors, 2016: Greening of the earth and its drivers. Nat. Climate Change, 6, 791-795, https://doi.org/10.1038/ nclimate 3004.

- S. Piao, X. Lian, R. B. Myneni, S. Peng, and H. Yang, 2017: Attribution of seasonal leaf area index trends in the northern latitudes with "optimally" integrated ecosystem models. Global Change Biol., 23, 4798-4813, https://doi.org/10.1111/ gcb.13723. 